Article

\title{
Multi-Objective Optimum Design of Hybrid Renewable Energy System for Sustainable Energy Supply to a Green Cellular Networks
}

\author{
Md. Sanwar Hossain ${ }^{1, *(\mathbb{D}}$, Abu Jahid ${ }^{2}{ }^{(0}$, Khondoker Ziaul Islam ${ }^{3}{ }^{(D}$, Mohammed H. Alsharif ${ }^{4}(\mathbb{D}$ \\ and and Md. Fayzur Rahman ${ }^{5}$ \\ 1 Department of Electrical, Electronic and Communication Engineering, Military Institute of Science \& \\ Technology (MIST), Dhaka 1216, Bangladesh \\ 2 Electrical \& Computer Engineering, University of Ottawa, Ottawa, ON K1N 6N5, Canada; \\ ajahi011@uottawa.ca \\ 3 Department of Electrical and Electronic Engineering, Bangladesh University of Business \& Technology \\ (BUBT), Dhaka 1216, Bangladesh; ziaiut@gmail.com \\ 4 Department of Electrical Engineering, College of Electronics and Information Engineering, \\ Sejong University, 209 Neungdong-ro, Gwangjin-gu, Seoul 05006, Korea; malsharif@sejong.ac.kr \\ 5 Department of Electrical and Electronic Engineering, Green University of Bangladesh (GUB), \\ Dhaka 1216, Bangladesh; drfayzur@eee.green.edu.bd \\ * Correspondence: sanwareee@gmail.com; Tel.: +880-1719-452910
}

Received: 24 March 2020; Accepted: 22 April 2020; Published: 26 April 2020

check for updates

\begin{abstract}
A hybrid solar photovoltaic (PV)/biomass generator (BG) energy-trading framework between grid supply and base stations (BSs) is proposed in this article to address the power crisis of the utility grid, to enhance energy self-reliance, and to downsize the cost. The optimal size, technical criteria, energy generation, and different types of costs have been evaluated considering the dynamic behavior of solar radiation, traffic arrival intensity, and average biomass energy potential. Additionally, the wireless network performance in terms of total achievable throughput, spectral efficiency (SE), and energy efficiency (EE) are extensively examined using the MATLAB-based Monte-Carlo simulations taking multipath fading, system bandwidth, transmission power, and inter-cell interference (ICI) into consideration. The numerical results demonstrate that the energy-trading facility can achieve net present cost (NPC) and greenhouse gas saving up to $3.20 \%$ and $65.8 \%$, respectively. In the end, the performance of the hybrid solar PV/BG system has been thoroughly compared with the standalone solar PV, hybrid PV/wind turbine (WT), and hybrid $\mathrm{PV} /$ diesel generator (DG) systems under on-grid and off-grid configurations for benchmarking.
\end{abstract}

Keywords: cellular networks; hybrid energy; solar energy; biomass energy; sustainability; energy efficiency

\section{Introduction}

Telecom network operators are installing a higher number of BSs to meet the demand of ever-increasing data rate and the number of mobile subscribers across the world. The exponential growth of mobile networks and the corresponding demand of huge amount of energy has become a great challenge to the researchers and network operators due to the limited reservation, higher capital cost, and the negative impact of fossil fuel. The rapid and radical deployment of cellular base stations is pushing up the total energy demand, resulting in an enormous burden on the power grid and triggering harmful greenhouse gas emissions. Notably, the number of worldwide mobile subscribers had increased by 3\% between 2017 and 2019, which is approximately 7.9 billion in Q1 2019 [1]. It is 
expected that the number of worldwide mobile subscribers will be 8.9 billion [2] at the end of 2025 . According to the Global System for Mobile Communications Association (GSMA), Bangladesh has above 88 million unique subscribers at present, which will rise by 1.2 fold at the end of 2025, amounting to around 107 million [3]. It is identified that cellular networks consume much of the energy disbursed for the mobile communication industry, wherein the base station alone draws above $57 \%$ of the total energy expenditure [4]. The authors in Reference [5] mentioned that the annual energy consumed by the mobile industry has increased from 219 TWh in 2007 to 519 TWh in 2019. This consumption rises at a yearly rate of $10 \%$. Moreover, the world energy consumption is projected to rise by around $27 \%$, which is equivalent to 3743 million tons of oil from 2018 to 2040 as reported by the International Energy Agency (IEA) [6].

As much of the consumption of energy is mainly supplied by fossil fuel, the telecommunication sector has become a key emitter of carbon contents. According to Reference [4], the amount of carbon footprint released by the cellular network will rise to $179 \mathrm{MtCO}_{2}$ by 2020 , which accounts for $51 \%$ of the total carbon contents of the information and communication technology (ICT) sector. The rapidly increasing energy demand by the ICT industry not only places heavy pressure on the public utility grid but also exerts a negative impact on the economy apart from greenhouse gas (GHG) emissions [7]. As a consequence, the capital expenditures (CAPEXs) and operational expenditures (OPEXs) have significantly increased since a major portion of the OPEX entails energy charges [8,9]. Moreover, traditional diesel generator-powered BSs deployed in remote locations significantly increase the OPEX value together with carbon footprints $[5,10]$.

Considering the above circumstances and due to the growing awareness of pollution rate and economical perspectives, renewable energy harvesting (REH) technology plays a significant role in promoting green mobile communication [11,12]. The REH technology primarily aims to find out the sustainable energy sources, to minimize the capital cost, and to reduce the carbon contents by maintaining the guaranteed quality of services (QoS) $[2,4,8]$. Renewable energy sources such as solar, wind, biomass, hydropower, etc. have various benefits, as these sources are reuseable, free, clean, and available in many areas throughout the year $[2,8,13]$. Additionally, REH technique can be the potential efficient option in the remotely situated off-grid BS, where transportation of fuel is quite challenging due to rough terrain and is expensive. Being inspired by the potential advantages of green energy (RE) sources, cellular network operators are highly interested in installing locally available RE-focused cellular BSs, which can radically diminish the pressure on fossil fuel and enhance network performance [2,14]. Despite the above inherent benefits, renewable energy-enabled base stations are facing some fundamental challenges owing to the dynamic and intermittent behavior of RE sources over time and space, which may cause energy deficiency/energy outage and thus degrade the QoS. However, these problems can be overcome by combining renewable energy sources with the traditional nonrenewable energy source or by the hybridization of two/three RE sources or a single RE source with sufficient battery unit or grid-tied RE sources.

Bangladesh is a tropical and the fourth rice-producing country in the world. The average sunlight intensity of the country is $4.59 \mathrm{kWh} / \mathrm{m}^{2} /$ day, which has the potential of generating around 70 PWh solar energy each year; that is 3000 times higher than the total electrical energy generation of the country $[15,16]$. In the meantime, rice husk-based average biomass capacity of the country is $30 \mathrm{t} /$ day [17,18], for which energy potential is $1344.99 \mathrm{PJ}$ that is equivalent to $373.71 \mathrm{TWh}$ of electrical energy [19]. The authors in Reference [20] reported that, at the end of 2030, Bangladesh will able to generate 7682 GWh energy from the rice husk with a total capacity of $1066 \mathrm{MW}$. Developing an eco-sustainable power supply for the next-generation mobile network by integrating solar PV with biomass is an effective step for a country like Bangladesh where biomass and solar energy are abundant. Combined solar PV/biomass energy also helps to enhance the network reliability with guaranteed quality of services for its integrated nature [18,21]. Along with other factors, the concept of on-site locally harvested surplus energy trading is adopted in this paper. The realization of energy cooperation mechanism in a certain zone is widely discussed in literature [14]. The energy-sharing policy among 
collocated BSs in a cluster requires installation of additional overhead power cable which is not a plausible design in a wide-scale range. The fundamental difference between the present project and the others is the energy cooperation, i.e., electricity-trading concept developed between grid connection and closely located BSs in order to improve energy efficiency and to essentially eliminate additional resistive line deployment like the aforementioned one. The facility of selling excess electricity will improve the deficiency of public utility grid. The key contributions of this work are summarized below:

- To determine the optimal system architecture and techno-economic feasibility of the hybrid solar PV and biomass focused supply system using HOMER optimization software under various system bandwidth and transmission power. Moreover, the concept of selling excess electricity to the grid is developed for curtailing grid electricity, increasing energy efficiency and cost-effectiveness as well.

- To examine the performance of the wireless network in terms of throughput, spectral efficiency, energy efficiency, and energy efficiency gain considering a few limiting factors such as shadow fading and inter-cell interference using MATLAB-based Monte-Carlo simulations considering the dynamic traffic profile.

- To compare the performance of the proposed system with that of the standalone solar PV, hybrid $\mathrm{PV} / \mathrm{WT}$, and hybrid PV/DG in terms of different performance metrics for further validation.

The rest of the manuscript is organized as follows: Section 2 includes a thorough study of the related literature. A concise description of the system architecture along with various system components is presented in Section 3. Meanwhile, cost modeling and optimization formula are described in Section 4. Section 5 outlines the performance analysis including the simulation setup, energy yield analysis, performance metrics, cost analysis, and greenhouse gas emissions. Finally, Section 6 draws the conclusion of the paper, addressing the key findings.

\section{Literature Review}

Over the last decade, a number of research works have been completed by the telecom operators and academia to develop an eco-friendly and sustainable green cellular network for the next-generation mobile communications utilizing the locally available renewable energy sources [22-24]. The prime concern of green mobile communication is to enhance network performance in the field of throughput, energy efficiency, operational expenditure, and greenhouse gas discharge.

Numerous research works related to the challenges and potential solutions to the problems of renewable energy-focused green cellular BSs have been presented in literature. References $[4,16,25]$ introduce a single renewable energy solar PV-based supply scheme along with adequate battery bank addressing the key factors of designing solar PV-enabled cellular BSs. In these works, various performance parameters such as energy yield, economic yield, and environmental aspects have been critically analyzed considering the dynamic nature of solar intensity. Although these works provide an exclusive method of harvesting energy from the standalone solar PV source, energy deficiency/outage may occur due to the single technology. The authors in References [26-29] investigated the optimal system architecture and technical criteria for installing hybrid solar PV/DG powered off-grid BSs throughout the world using the HOMER platform. The combined utilization of solar PV and DG could mitigate the fluctuations of renewable energy production and improve the QoS. References [30-32] evaluated the optimization of an aggregated solar PV/WT power system for standalone BS sites. The modeling and optimal sizing of combined (solar and hydro) and DG system for powering the off-grid remote BSs is presented in Reference [27]. Bajpai et al. [33] introduced three types of renewable energy: (i) solar PV/battery system, (ii) solar PV/fuel cell system, and (iii) solar PV/fuel cell/battery systems for feeding the rural cellular network. To attain the full advantages of renewable energy technology, advanced battery modeling, and constraints, optimization is a crucial factor. The authors in References [34,35] proposed a novel multi-objective optimization framework to optimize charging profiles of Li-ion battery. 
For improving energy efficiency, numerous techniques have been proposed through research in this area but it is not yet saturated $[29,36]$. Moreover, the performance of the green cellular networks is directly related to the dimensioning of the optimal system architecture due to the temporospatial variation of the traffic pattern and renewable energy resources [30,37,38]. The authors in References $[30,39,40]$ explain a hybrid-powered off-grid base station for improving the energy efficiency, which will share the surplus energy among the nearby BSs through a low resistive exterior power line. In these papers, the challenges of inter- BS excess electricity sharing along with maximum utilization of renewable energy are discussed, and potential solutions in terms of energy, capital cost, and cleanness issues are presented. Moreover, sensitivity analysis has been carried out using HOMER software in order to find out the optimal system architecture under different parameters such as system bandwidth (BW), transmission power, and daily solar/wind profile. Reference [41] proposed a coordinated multipoint (CoMP)-based green cellular networks which can increase the spectral efficiency of the wireless network by reducing the inter-cell interference. In this work, the authors investigated only the spectral efficiency of the 5G cellular networks without considering energy efficiency.

A mechanism of transferring energy from one BS to another via a low resistive power line has been analyzed in Reference [39]. However, energy sharing via external physical wire is an efficient way for small areas but it is not suitable for long-haul communication links. Energy exchanging within the BSs through smart grid (SG) infrastructure is discussed in Reference [42]. Subsequently, Farooq et al. [43] proposed a combined green energy sharing technique, where an external physical connection is used to exchange electricity among the neighboring BSs and smart grid technology is used to share the locally generated energy. References $[44,45]$ proposed an infrastructure sharing model for improving the energy efficiency, where the same radio access network (RAN) will be shared by the multiple network operators. The authors in Reference [46] expressed the significant improvement of energy efficiency and reduction of the grid power consumption integrating both base station sleep mode and green energy-harvesting technique. Reference [47] explored the on/off mechanism of small BSs according to the dynamic traffic profile with hybrid supplies for increasing the energy efficiency (EE) performance. Improving network performance by the switching off technique is not adequate for heavy traffic load BS, and sleep mode provision may deteriorate QoS due to lack of proper coordination. However, all these works represent a unique method for fulfilling the BS energy demand with higher EE and for sharing the excess electricity among them without sacrificing its own performance. In the end, energy cooperation mechanisms are feasible when the locally available green energy production is higher than the BS energy requirement particularly for shorter geographical distance.

In recent years, renewable energy-powered cellular network with a power grid line has drawn deep attention by the telecom operators because of potential advantages and dynamic nature of renewable energy [48]. Moreover, due to the advancement of different energy management techniques $[49,50]$, renewable energy-focused grid-tied wireless networks can significantly improve the energy efficiency performance, network coverage area, and electricity exchanging facility. References [51-53] introduce a grid-tied modern cellular base station that is primarily powered by the solar PV where backup power is provided by the battery bank and traditional grid supply. In these works, the authors propose a dynamic point selection and joint transmission coordinated multipoint transmission technique-based cellular networks, with dynamic inter-BS green electricity exchanging policy. Moreover, the performance of the system has been analyzed critically using MATLAB-based Monte-Carlo simulations considering the realistic traffic pattern. The authors in Reference [54] introduce a grid-tied renewable energy-assisted heterogeneous cellular networks (HetNets) for which transmission power is optimized by the novel relay selection and power allocation algorithm. In these works, the key challenges of utilizing the maximum amount of renewable energy by reducing the grid energy consumption are critically analyzed by installing the different relay stations (RSs) in a network. References [55] evaluated the optimization of grid power consumption for hybrid renewable energy and the grid powered HetNets. The prime concern of this work is to reduce the 
grid power cost by controlling the transmitted power and stored energy considering the coverage probability constraint. These unique methods can overcome the drawback of using renewable energy and help to improve energy efficiency ensuring QoS, where the electrical power line is available.

\section{System Model}

This section represents the concise description of the major components of the proposed system and the corresponding mathematical modeling in the context of green mobile communications. System activity can be classified into three parts: (i) hybrid PV/BG system independently supplies the BSs energy requirement; (ii) a certain amount of excess electricity is stored in the storage device and a major percent of excess electricity is sold to the power grid; and (iii) if the PV/BG system fails to support the BS energy demand primarily, backup power is provided by the storage devices and grid system. The abbreviations and symbols used in this manuscript are summarized in Table 1.

Table 1. Summary of the abbreviations and symbols.

\begin{tabular}{cccc}
\hline Abbreviation & Meaning & Abbreviation & Meaning \\
\hline BW & Bandwidth & $E_{\text {loss }}$ & Total losses \\
COE & Cost of electricity & $E_{r e m}$ & Remaining green energy \\
EE & Energy efficiency & $E_{\text {sale }}$ & Sold energy \\
GHG & Greenhouse Gas & $E_{\text {short }}$ & Green energy shortage \\
NPC & Net present cost & $N_{b a t t}$ & Number of batteries \\
QoS & Quality of service & $P_{T X}$ & BS Transmit power \\
R & Solar radiation & $R_{P V}$ & Rated capacity of the solar PV panel \\
$E_{\text {Excess }}$ & Excess electricity & $\eta_{c}$ & Converter efficiency \\
$E_{g e n}$ & Green energy generation & $\lambda$ & Charging efficiency \\
$E_{\text {grid }}$ & Grid energy & $\chi$ & BS Traffic load \\
\hline
\end{tabular}

\subsection{Network Model}

In this work, a two-tier downlink long term evaluation (LTE) cellular macro base station with hexagonal shape has been considered. The architecture of the proposed system with $2 / 2 / 2$ antenna patterns is shown in Figure 1. In general, the BS consists of transceivers (TRXs) unit, power amplifiers (PAs) unit, a radio frequency (RF) unit, a baseband (BB) unit for processing and coding signal, and a DC-DC power supply [56]. The macro-BSs are powered by a hybrid solar PV/BG scheme along with a smart energy management unit (EMU), inverter, and sufficient storage devices. An EMU is used to protect the battery from overcharging and deep discharging. The BS is generally a DC load, but it also includes some AC loads as auxiliary equipment, such as air conditioning and lighting. Here, we consider a 30-W AC lamp only, which is connected to the BS from 6 PM to 6 AM. For the remote radio head (RRH)-enabled macro-base station, no cooling system is required since a fiber optic link is established instead of a coaxial cable between the antenna and baseband unit. Besides, an electrical grid system is connected to the hybrid PV/BG system in a bidirectional way for exchanging electricity selling facility to the grid during surplus production and scarcity in order to ensure reliable operation. The term $2 / 2 / 2$ represents a three-sector site with two antennas per sector. 


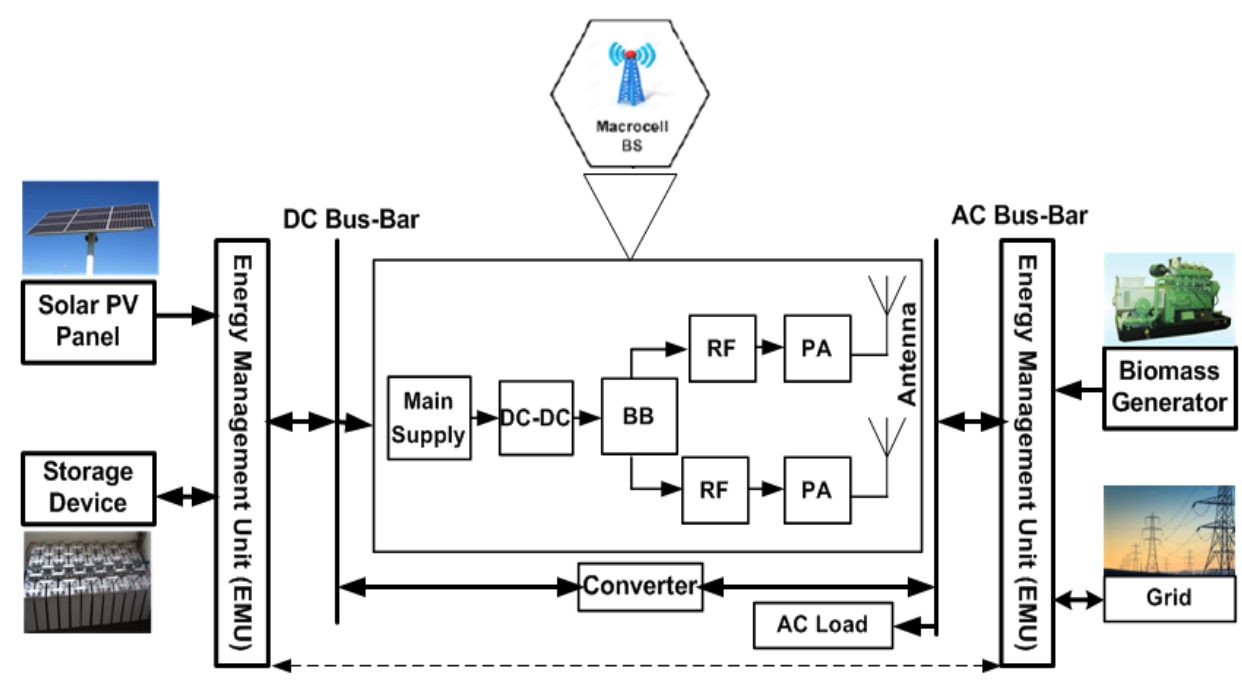

Figure 1. Architecture of the grid-tied hybrid PV/biomass generator (BG) system for a macro-BS.

\subsection{Solar PV Panel}

Several solar cells are connected in series/parallel to form a solar PV array, which converts the sunlight into DC electrical energy [57]. HOMER calculates the total generated energy by the solar PV panel using the following equation [58]

$$
E_{P V}=R_{P V} \times P S H \times \eta_{P V} \times 365 \text { days } / \text { year }
$$

where $R_{P V}$ is the solar PV panel-rated capacity in $\mathrm{kW}, \mathrm{PSH}$ is the peak solar which is similar to average daily solar irradiation, and $\eta_{P V}$ is the derating factor of the solar PV panel. There are many derating factors in a PV system design such as thet environment, PV system, installation, cost, etc. In this work, a standard value of derating factor 0.9 is used for dimensioning solar PV panel. The term dimensioning of solar PV panel means the optimal sizing of the solar PV panel. Figure 2 depicts the annual solar radiation profile along with the clearness index (CI) of the selected area. The average value of solar intensity and clearness index of the considered location are respectively $4.59 \mathrm{kWh} / \mathrm{m}^{2} /$ day and 0.503, which imply that Bangladesh has a better opportunity for producing electricity from sunlight. The required number of solar PV panels $\left(N_{P V}\right)$ to produce a specific output $\left(P_{p}\right)$ can be formulated as follows [30]:

$$
N_{P V}=\frac{P_{p}}{P_{\max }}
$$

where $P_{\max }$ is the maximum power of the solar PV panel.

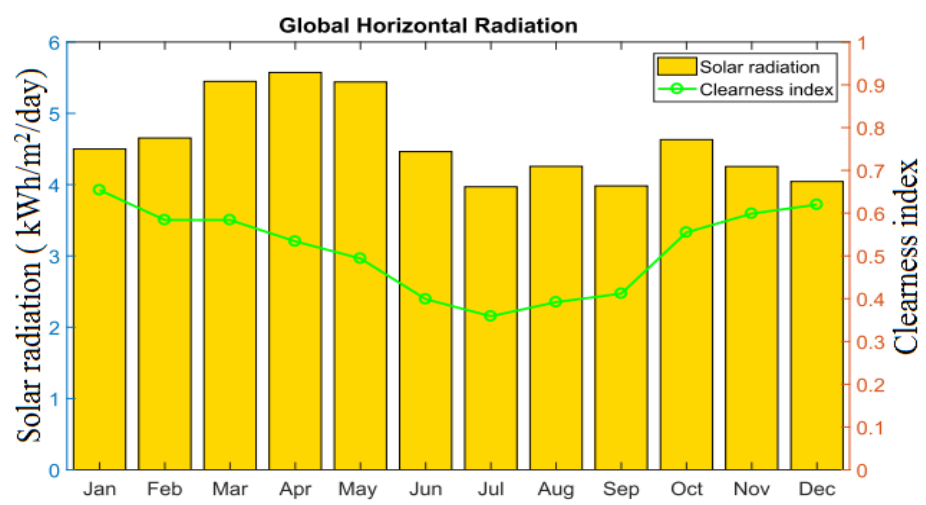

Figure 2. Daily average solar intensity profile and clearness index of the selected area. 


\subsection{Biomass Generator}

In Bangladesh, biomass as a renewable energy source includes mainly agricultural crop residues, wood residues, animal waste, municipal solid waste, etc. Among the various biomass resources, agricultural crop residue rice husk has been selected in this simulation. The maximum amount of rice rusk to be collected is considered around 20\% (9t/day) of total available rice husk in the area, and the cost of biomass is taken as $\$ 30 / t[59,60]$. Bangladesh has enough potential for producing a large amount of electricity utilizing this amount of rice husk. Power generation from the biomass gasifier system depends on various factors such as the calorific value of biomass $\left(C V_{B M}\right)$, biomass availability $\left(T_{B M}\right)$, the operating hour of the biomass generator per day $\left(t_{o p}\right)$, and overall conversion efficiency of biomass system $\left(n_{B M}\right)$ which can be expressed as follows [59,60]:

$$
P_{B G}=\frac{T_{B M}(\mathrm{t} / \text { year }) \times C V_{B M} \times \eta_{B M} \times 1000}{365 \times 860 \times t_{o p}}
$$

The amount of renewable energy harvested by the biomass generator can be expressed as follows [59,60]:

$$
E_{B G}=P_{B G}(365 \times 24 \times \text { capacity factor })
$$

where the capacity factor is the ratio of actual electrical energy output to the maximum possible electrical energy output over a given period of time. In this work, the set capacity factor is 0.389 .

\subsection{Converter}

A device that is used to change the AC voltage into DC voltage or vice-versa is known as a converter, wherein the $\mathrm{AC}$ to DC converter is known as the rectifier and the DC to AC converter is known as an inverter. HOMER calculates the size of the inverter as a function of maximum AC load $\left(L_{A C}\right)$, inverter efficiency $\left(\eta_{i n v}\right)$, and safety factor $\left(\sigma_{s f}\right)$ by the following equation [58]:

$$
C_{i n v}=\left(\frac{L_{A C}}{\eta_{i n v}}\right) \times \sigma_{s f}
$$

\subsection{Storage Devices}

Different characteristics of the battery bank such as state of battery charge (SOC), voltage, efficiency, depth of discharge, autonomy, and lifetime play an important role in the design of the optimal system architecture. The maximum state of charge $\left(S O C_{\max }\right)$ of the battery represents the nominal capacity of the battery bank, and the minimum state of charge $\left(S O C_{\min }\right)$ of the battery is the lower limit of the discharge value. The depth of discharge of the battery bank $\left(B_{D O D}\right)$ indicates maximum energy that will be supplied from the battery bank and can be calculated as follows [58]:

$$
B_{D O D}=\left(1-\frac{B_{S O C_{\text {min }}}}{100}\right)
$$

The battery bank autonomy $\left(B_{a u t}\right)$ is another key factor in order to determine the potential number of days that the battery bank can feed the BS load requirement without any support from the hybrid system and is formulated as follows [58]:

$$
B_{\text {aut }}=\frac{N_{\text {batt }} \times V_{\text {nom }} \times Q_{\text {nom }} \times B_{D O D} \times(24 \mathrm{~h} / \text { day })}{L_{B S}}
$$

where $N_{\text {batt }}$ is the number of batteries, $V_{\text {nom }}$ is the nominal voltage of a single battery, $Q_{\text {nom }}$ is the nominal capacity of a single battery, and $L_{B S}$ is the average daily BS load. 
The longer battery lifecycle $\left(L_{b a t t}\right)$ can minimize the net present cost over the project lifecycle by reducing the replacement cost. The battery lifecycle is directly related to the battery throughput and battery float life. HOMER calculates the battery lifecycle based on the following equation [58]:

$$
L_{\text {batt }}=\min \left(\frac{N_{\text {batt }} \times Q_{\text {life }}}{Q_{\text {thp }}}, B_{f}\right)
$$

where $Q_{\text {life }}$ is the lifetime throughput of a single battery. The annual battery throughput in $\mathrm{kWh} /$ year is represented by $Q_{t h p}$. The battery float life is represented by $B_{f}$.

The number of batteries connected in series $\left(N_{\text {batt }}^{\text {series }}\right)$ and connected in parallel $\left(N_{\text {batt }}^{\text {parallel }}\right)$ can be found by the following equations:

$$
\begin{aligned}
N_{\text {batt }}^{\text {series }} & =\frac{V_{b b}}{V_{\text {nom }}} \\
N_{\text {batt }}^{\text {parallel }} & =\frac{N_{\text {total }}}{N_{\text {batt }}^{\text {series }}}
\end{aligned}
$$

where $V_{b b}$ is the DC bus bar voltage and $V_{\text {nom }}$ is the nominal voltage rating of the chosen battery model.

\subsection{BS Power Profile}

Modeling and dimensioning of the sustainable supply system depends heavily on the BS power requirement. In a practical cellular network, incoming traffic profile is time-varying and energy consumption by the BSs is directly related to the traffic volumes as shown in Figure 3. The total power consumption of a BS as a function of traffic intensity $(\chi)$ can be represented as follows [56]:

$$
P_{\text {in }}= \begin{cases}N_{T R X}\left[P_{1}+\Delta_{p} P_{T X}(\chi-1)\right], & \text { if } 0<\chi \leq 1 \\ N_{\text {TRX }} P_{\text {sleep }}, & \text { if } \chi=0\end{cases}
$$

where $P_{1}=P_{0}+\Delta_{p} P_{T X}$ is the maximum power consumption of a BS sector, $N_{T R X}$ is the total number of the transceiver, $\Delta_{p}$ is the load dependency power gradient, and $P_{0}$ is the consumption at idle state. The scaling parameter $\chi$ is the load share, where $\chi=1$ indicates a fully loaded system and $\chi=0$ indicates an idle system. Furthermore, a BS without any traffic load enters into sleep mode with lowered consumption, $P_{\text {sleep }}$. The key parameters of the macro-BS are shown in Table 2.

Power losses are directly related to the power consumption of the other component such as DC-DC regulator, main supply, and cooling system which may be denoted respectively by $\sigma_{D C}, \sigma_{M S}$, and $\sigma_{\text {cool }}$. The maximum power consumption of the base station is determined as follows [56]:

$$
\begin{gathered}
P_{1}=\frac{P_{B B}+P_{R F}+P_{P A}}{\left(1-\sigma_{D C}\right)\left(1-\sigma_{M S}\right)\left(1-\sigma_{c o o l}\right)} \\
P_{1}=\frac{N_{T R X} \frac{B W}{10 M H z}\left(P_{B B}^{\prime}+P_{R F}^{\prime}\right)+\frac{P_{T X}}{\eta_{P A}\left(1-\sigma_{\text {feed }}\right)}}{\left(1-\sigma_{D C}\right)\left(1-\sigma_{M S}\right)\left(1-\sigma_{c o o l}\right)}
\end{gathered}
$$

where $N_{T R X}$ is the total number of antennas in a base station and $P_{T X}$ is the maximum transmission power in Watt. The $P_{B B}^{\prime}$ and $P_{R F}^{\prime}$ respectively are the BB and RF power consumption for the given $10 \mathrm{MHz}$ system bandwidth as shown in Table 3. 


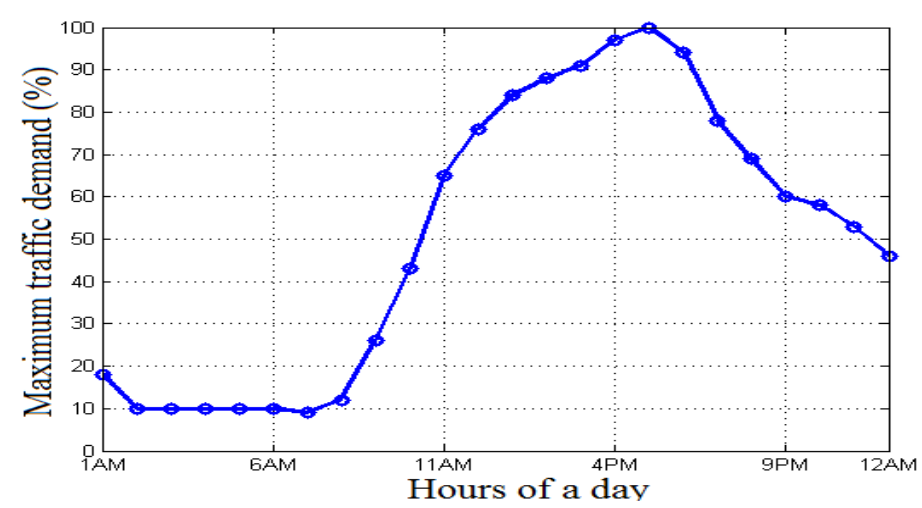

Figure 3. Dynamic traffic profile over $24 \mathrm{~h}$.

Table 2. Key parameters of the macro-base station [56].

\begin{tabular}{lccccc}
\hline BS Type & $\boldsymbol{N}_{\boldsymbol{T R X}}$ & $\boldsymbol{P}_{\boldsymbol{T X}}(\mathrm{W})$ & $\boldsymbol{P}_{\mathbf{0}}(\mathbf{W})$ & $\boldsymbol{\Delta}_{\boldsymbol{P}}$ & $\boldsymbol{P}_{\text {sleep }}(\mathrm{W})$ \\
\hline Macro RRH & 6 & 20 and 40 & 84 & 2.8 & 56 \\
\hline
\end{tabular}

Table 3. Macro-BS power breakdown under peak load and $10 \mathrm{MHz}$ bandwidth [56].

\begin{tabular}{clcc}
\hline Components & Parameters & Macro BS & Macro BS \\
\hline BS & $P_{T X}(\mathrm{~W})$ & 20 & 40 \\
& Feeder loss $\sigma_{\text {feed }}(\mathrm{dB})$ & 0 & 0 \\
\hline PA & Back-off $(\mathrm{dB})$ & 8 & 8 \\
& Max PA out $(\mathrm{dBm})$ & 51 & 51 \\
& PA efficiency $\eta_{P A}(\%)$ & 31.1 & 31.1 \\
\hline & Total PA, $\frac{P_{T X}}{\eta_{P A}\left(1-\sigma_{\text {feed }}\right)}(\mathrm{W})$ & 64.4 & 128.6 \\
\hline RF & $P_{T X}(\mathrm{~W})$ & 6.8 & 6.8 \\
& $P_{R X}(\mathrm{~W})$ & 6.1 & 6.1 \\
\hline Total RF, $P_{R F}^{\prime}(\mathrm{W})$ & 12.9 & 12.9 \\
\hline BB & Radio $($ inner Tx/Rx) $(\mathrm{W})$ & 10.8 & 10.8 \\
& Turbo code $($ outer Tx $/ \mathrm{Rx})(\mathrm{W})$ & 8.8 & 8.8 \\
& Processors $(\mathrm{W})$ & 10 & 10 \\
\hline Total BB, $P_{B B}^{\prime}(\mathrm{W})$ & 29.6 & 29.6 \\
\hline DC-DC & $\sigma_{D C}(\%)$ & 7.5 & 7.5 \\
Cooling & $\sigma_{\text {cool }}(\%)$ & 0 & 0 \\
Mains Supply & $\sigma_{M S}(\%)$ & 9 & 9 \\
\hline Sectors & & 3 & 3 \\
Antennas & & 2 & 2 \\
\hline Total power $(\mathrm{W})$ & & $\mathbf{7 5 4 . 8}$ & $\mathbf{1 2 1 9 . 6}$ \\
\hline & & & \\
\hline
\end{tabular}

\subsection{Reliability Model}

The annual capacity shortage $\left(R_{C S}\right)$ is an indicator of power reliability which is expressed as the ratio of yearly energy deficiency $\left(E_{C S}\right)$ to the yearly base station energy demand $\left(E_{B S}\right)$.

$$
R_{C S}=\frac{E_{C S}}{E_{B S}}
$$

In this simulation setup, energy deficiency has been considered zero percent, which can be defined as

$$
E_{C S}=E_{B S}-E_{g e n}
$$


where $E_{g e n}$ is the annual energy generated by the system, which can be expressed as

$$
E_{g e n}=E_{P V}+E_{B G}
$$

System reliability can be achieved when the BS energy requirement is fulfilled by the generated energy over the entire lifetime. For the suggested hybrid PV/BG system, excess electricity $\left(E_{\text {Excess }}\right)$ is generated under the condition when total energy generation is higher than the BS load demand. Excess electricity can be computed as follows:

$$
E_{\text {Excess }}=E_{\text {gen }}-E_{\text {sales }}-E_{B S}-C_{\text {loss }}-B_{\text {loss }}
$$

where $C_{\text {loss }}, B_{\text {loss }}$, and $E_{\text {sales }}$ respectively represent the annual converter loss, battery loss, and grid sales energy.

\subsection{Energy Efficiency Model}

In this paper, a log-normally distributed shadow fading channel has been assumed for identifying the signal to the interference plus noise ratio (SINR). If $d$ is the distance between the receiver and transmitter, then the path loss model can be formulated as follows [30]:

$$
P L(d)=P L\left(d_{0}\right)+10 \alpha \log _{10}\left(\frac{d}{d_{0}}\right)+X_{\sigma}
$$

where $P L\left(d_{0}\right)$ is the path loss component at the near field reference distance $\left(d_{0}\right)$ and $\alpha$ is the exponent of path loss. Path loss for reference distance can be determined from the free-space path loss equation.

For the $k^{\text {th }}$ user equipment (UE), the received power at a distance $d=d^{i, k}$ from the $i^{\text {th }}$ BS $\beta_{i}$ is calculated by [30]

$$
P_{r x}^{i, k}=P_{t x}^{i, k}-P L(d)+X_{\sigma}
$$

where $P_{t x}^{i, k}$ is the transmitted power in $\mathrm{dBm}$ and $X_{\sigma}$ is the amount of shadow fading modeled as a zero-mean Gaussian random variable with a standard deviation $\sigma \mathrm{dB}$. The transmit power $P_{t x}^{i, k}$ from BS $i$ to UE $k$ satisfies $\sum_{k \epsilon U} P_{t x}^{i, k} \leq P_{i}^{\max }$, where $P_{i}^{\max }$ is the radio frequency output power of the base station at its maximum traffic profile and $U$ is the number of active user equipment in this BS.

The inter-cell interference (ICI), $P_{k, \text { inter }}$, can be calculated by [30]

$$
P_{k, \text { inter }}=\sum_{m \neq i}\left(P_{r x}^{m, k}\right)
$$

Then, the received SINR at the $k^{\text {th }}$ UE from BS $\beta_{i}$ can be determined by [30]

$$
\operatorname{SINR}_{i, k}=\frac{P_{r x}^{i, k}}{P_{k, \text { inter }}+P_{k, \text { intra }}+P_{N}}
$$

where $P_{k, \text { intra }}$ is the intra-cell interference, $P_{N}$ is the additive white Gaussian noise (AWGN), and power given by $P_{N}=-174+10 \log _{10}(B W)$ in $\mathrm{dBm}$ with $B W$ is the bandwidth in Hz. Notwithstanding, the orthogonal frequency division multiple access (OFDMA) technique in the LTE system includes zero intra-cell interference.

The term energy efficiency is used to calculate the performance of the network and can be identified as the number of bits transmitted per Joule of energy. In this paper, the term energy efficiency is denoted as the ratio of total network throughput and total power consumed by the network. 
According to Shanon's information capacity theorem, total achievable throughput in a network at time $t$ can be evaluated as follows [30]:

$$
C_{\text {total }}(t)=\sum_{k=1}^{U} \sum_{i=1}^{N} B W \log _{2}\left(1+S I N R_{i, k}\right)
$$

where $N$ is the number of transmitting BSs and $U$ is the total number of UEs in the network. Then, the energy efficiency and spectral efficiency performance of a network can be approximated by the following equations [30]:

$$
\begin{gathered}
N_{E E}=\frac{C_{\text {total }}}{P_{\text {net }}} \\
\eta_{S E}=\frac{C_{\text {total }}}{B W}
\end{gathered}
$$

where $P_{\text {net }}$ is the net power consumed in all the BSs at time $t$, which is estimated using Equation (11). The performance metrics such as throughput, spectral efficiency, and energy efficiency of the introduced networks are evaluated with the help of Monte-Carlo-based MATLAB simulation. The simulations are performed by averaging above 10,000 iterations considering the realistic traffic profile. It is also considered that each user is associated with at least one resource block (RB). Table 4 summarizes the key parameters of the simulation process.

Table 4. Key parameters for MATLAB-based Monte-Carlo simulation setup [30].

\begin{tabular}{lc}
\hline Parameters & Value \\
\hline Resource block (RB) bandwidth & $180 \mathrm{kHz}$ \\
System bandwidth, BW & $5,10,15,20 \mathrm{MHz}$ \\
Carrier frequency, $f_{c}$ & $2 \mathrm{GHz}$ \\
Duplex mode & $\mathrm{FFD}$ \\
Cell radius & $1000 \mathrm{~m}$ \\
BS Transmission power & $43 \mathrm{and} 46 \mathrm{dBm}$ \\
Noise power density & $-174 \mathrm{dBm} / \mathrm{Hz}$ \\
Number of sectors & 3 \\
Number of antennas & 2 \\
Reference distance, $d_{0}$ & $100 \mathrm{~m}$ \\
Path loss exponent, $\alpha$ & 3.574 \\
Shadow fading, $X_{\sigma}$ & $8 \mathrm{~dB}$ \\
Access technique, DL & OFDMA \\
Traffic model & Randomly distributed \\
\hline
\end{tabular}

\subsection{Energy Trading Policy}

This subsection presents the policy of trading energy between the hybrid supply system and the electrical grid system. The energy trading policy can be divided into two cases:

\section{Case I: Sufficient Green Energy Production}

If the green energy generation, $E_{\text {gen }}^{i}(t)$, is sufficient, it will share green energy to the electrical grid system. Case I can be expressed as follows: $E_{\text {gen }}^{i}(t) \geq E_{B S}^{i}(t)+E_{\text {loss }}^{i}(t)$, where $E_{\text {gen }}^{i}(t)$ is the total amount of renewable energy generation at time $t$ for $i^{\text {th }} \mathrm{BS}$ and $E_{\text {loss }}^{i}(t)$ is the associated loss during this time. $E_{\text {gen }}^{i}(t)$ and $E_{\text {loss }}^{i}(t)$ can be calculated as follows:

$$
\begin{gathered}
E_{\text {gen }}^{i}(t)=E_{D C}(t)+E_{A C}(t)=E_{P V}(t)+E_{B G}(t) \\
E_{\text {loss }}^{i}(t)=B_{\text {loss }}^{i}(t)+C_{\text {loss }}^{i}(t)
\end{gathered}
$$


The remaining harvested energy, $E_{r e m}^{i}(t)$, in the battery bank (BB) after fulfilling the demand can be expressed as

$$
E_{\text {rem }}^{i}(t)=E_{\text {gen }}^{i}(t)-E_{B S}^{i}(t)-E_{\text {loss }}^{i}(t)
$$

After satisfying the demand of time $t$, available energy can be stored for the next time slot and can be expressed as

$$
E_{S}^{i}(t+1)=E_{\text {rem }}^{i}(t)+E_{\text {gen }}^{i}(t+1)-E_{B S}^{i}(t+1)-E_{\text {loss }}^{i}(t+1)
$$

However, the amount of energy captured in the battery bank can be estimated as follows:

$$
E_{S}^{i}(t+1)=\lambda \cdot E_{S}(t-1)+E_{g e n}(t) \times \eta_{c}-E_{B S}(t)
$$

where $E_{s}(t-1)$ is the energy storage capacity in the previous hour and $\lambda$ is the charging efficiency of the battery bank. For example, $\lambda=0.8$ implies that $20 \%$ energy is considered as battery loss and $80 \%$ stored energy is useful energy; $\eta_{c}$ is the converter efficiency.

It is worth mentioning that green energy sources charged the battery bank through EMU and that no grid procurement is involved in this scenario. Now, the selling of energy to the grid during surplus generation can be as follows:

$$
E_{\text {sur }}^{i}(t)=E_{\text {rem }}^{i}(t-1)+E_{\text {gen }}^{i}(t)-\lambda \cdot E_{B S}^{i}(t)
$$

where $\lambda$ represents the amount of backup energy to the respective $i$ th BS even after fulfilling its own demand.

\section{Case II: Insufficient Green Energy Production}

If the green energy generation, $E_{\text {gen }}^{i}(t)$, is not sufficient, it will receive energy from the electrical grid system. Case II can be expressed as follow: $E_{\text {gen }}^{i}(t)<E_{B S}^{i}(t)+E_{\text {loss }}^{i}(t)$

The total green energy shortage for the $i^{t h} \mathrm{BS}$ can be expressed as

$$
E_{\text {short }}^{i}(t)=E_{B S}^{i}(t)+E_{\text {loss }}^{i}(t)-E_{\text {gen }}^{i}(t)
$$

The remaining energy from the storage devices comes into the scenario in order to mitigate RE shortage, which can be presented as follows:

$$
E_{\text {sup }}^{i}(t)=E_{\text {short }}^{i}(t)-E_{B S}^{i}(t)
$$

$E_{\text {sup }}<E_{\text {short }}$ signifies the improvement of green energy utilization with the added benefits of backup storage device.

Thereafter, if $E_{\text {sup }}^{i}(t)<E_{B S}^{i}(t)+E_{\text {loss }}^{i}(t)$, then on-grid energy is procured for powering $\beta_{i}$ in order to ensure zero outage. Thus, the conventional grid energy denoted by $E_{\text {grid }}^{i}(t)$ at time $t$ can be given by

$$
E_{\text {grid }}^{i}(t)=(1+\lambda) E_{B S}^{i}(t)+E_{\text {loss }}^{i}(t)+E_{\text {sup }}^{i}(t)
$$

In this way, the energy-trading policy ensures the maximum utilization of renewable energy sources while maintaining the guaranteed quality of services.

\section{Cost Modeling and Optimization Formula}

In this work, HOMER optimization software has been used to determine the optimal architecture of the hybrid solar PV/biomass scheme that satisfies user-specified constraints with the lowest net present cost (NPC) including the initial capital costs (CC), replacement costs (RC), operation and maintenance costs (OMC), and salvage value (SV) during the project lifecycle. The net present cost of the system can be computed as follows [58]: 


$$
N P C=\frac{T A C}{C R F}=C C+R C+O M C-S V
$$

The term $T A C$ represents the total annualized cost, and CRF is the capital recovery factor. $T A C$ and $C R F$ can be calculated respectively by Equations (35) and (36) [58]:

$$
\begin{gathered}
T A C=T A C_{C C}+T A C_{R C}+T A C_{O M C} \\
C R F=\frac{i(1+i)^{N}}{(1+i)^{N}-1}
\end{gathered}
$$

where $i$ denotes the yearly interest rate and $N$ is the project lifecycle.

The capital cost which remains at the end of the project lifecycle is called salvage value and can be determined by [58]

$$
S V=C_{r e p}\left(\frac{R_{r e m}}{R_{\text {comp }}}\right)
$$

where $C_{r e p}, R_{r e m}$, and $R_{\text {comp }}$ are respectively the replacement cost of the component, the remaining lifetime, and the lifetime of the component.

For the hybrid solar PV and BG powered system, the net present cost also contains the fuel cost (FC), which can be formulated as follows [58]

$$
N P C=C C+R C+O M C+F C-S V
$$

The cost of electricity (COE) is identified as the ratio of the total annual cost to the annual energy generated $\left(E_{g e n}\right)$ by the system. Cost of electricity is calculated as the per-unit energy generation cost in $\$ / \mathrm{kWh}$, which is expressed as follows [58]:

$$
C O E=\frac{T A C}{E_{g e n}}=\frac{N P C \times C R F}{E_{g e n}}
$$

The hybrid power system design problem is formulated as an optimization problem with the objective function of minimizing NPC subject to various design and operational constraints. The aim of this work is to minimize energy deficiency through maximum utilization of solar and biomass energy in conjunction with excess electricity transferring to the grid which, in terms, reduces NPC [30]. The objective function of the system can be expressed as

$$
\begin{array}{ll}
\text { minimize } & N P C \\
\text { subject to } & E_{P V}+E_{B G}>E_{B S}, \\
& E_{P V}+E_{B G}+E_{\text {batt }}=E_{B S}+E_{\text {loss, }} \\
& E_{\text {Excess }}=E_{\text {gen }}-E_{\text {sales }}-E_{B S}-E_{\text {loss }}, \\
& E_{\text {battmin }} \leq E_{\text {batt }} \leq E_{\text {battmax }}
\end{array}
$$

where $E_{\text {loss }}$ involves both inverter and battery loss per year, $E_{B S}$ is the annual BS energy demand, and $E_{\text {batt }}$ is the electricity supplied by the storage devices.

The constraint in Equation (40b) ensures that the annual electricity generated by the suggested configuration carries the annual BS consumption. The total energy generation including battery backup satisfies the total BS energy requirement taken into two different losses that are pointed out in the constraint in Equation (40c). The constraint in Equation (40d) indicates that a measurable amount of excess electricity is preserved for future use and that a remarkable amount of electricity is sold to the grid. 


\section{Performance Evaluation}

\subsection{Simulation Setup}

For ensuring the long-term sustainability, the proposed system is simulated considering the twenty-year lifespan. The yearly interest rate deliberated in the simulation is $6.75 \%$, which influences the overall system expenditure. Additionally, ten percent power is reserved for future use to back up the BS load because energy scarcity or outage is not tolerable in the telecom sector. In this simulation setup, different sets of components size are selected for both on-grid and off-grid schemes to obtain the optimal system architecture. Additionally, the cost parameters of different instruments, typical lifetime of each module, and solar/biomass energy generation profile for a specific area are set in the HOMER background to identify both technical and economic aspects. The key parameters and their specifications have been summarized in Table 5 .

Table 5. Key parameters and their specifications for HOMER simulation setup [19,58].

\begin{tabular}{|c|c|c|}
\hline System Components & Parameters & Value \\
\hline \multirow[t]{3}{*}{ Resources } & Solar intensity & $4.59 \mathrm{kWh} / \mathrm{m}^{2} /$ day \\
\hline & Biomass available & $9 \mathrm{t} /$ day \\
\hline & Interest rate & $6.75 \%$ \\
\hline \multirow[t]{6}{*}{ Solar PV } & Operational lifetime & 25 years \\
\hline & Derating factor & 0.9 \\
\hline & System tracking & Dual-axis \\
\hline & Capital cost & $\$ 1 / W$ \\
\hline & Replacement cost & $\$ 1 / W$ \\
\hline & Operation and maintenance cost/year & $\$ 0.01 / \mathrm{W}$ \\
\hline \multirow[t]{6}{*}{ Biomass Generator } & Efficiency & $30 \%$ \\
\hline & Operational lifetime & $25,000 \mathrm{~h}$ \\
\hline & Capital cost & $\$ 0.66 / W$ \\
\hline & Replacement cost & $\$ 0.66 / W$ \\
\hline & Operation and maintenance cost/year & $\$ 0.05 / \mathrm{h}$ \\
\hline & Fuel Cost & $\$ 30 / \mathrm{t}$ \\
\hline \multirow[t]{3}{*}{ Grid } & Energy purchase price & $\$ 0.122 / \mathrm{kWh}$ \\
\hline & Energy sellback price & $\$ 0.110 / \mathrm{kWh}$ \\
\hline & Demand charge & $\$ 0.350 / \mathrm{kW} /$ month \\
\hline \multirow[t]{5}{*}{ Diesel Generator } & Efficiency & $40 \%$ \\
\hline & Operational lifetime & $25,000 \mathrm{~h}$ \\
\hline & Capital cost & $\$ 0.66 / \mathrm{W}$ \\
\hline & Replacement cost & $\$ 0.66 / W$ \\
\hline & Operation and maintenance cost/year & $\$ 0.05 / \mathrm{h}$ \\
\hline \multirow[t]{7}{*}{ Battery } & Round trip efficiency & $85 \%$ \\
\hline & $B_{S o C_{\min }}$ & $30 \%$ \\
\hline & $V_{\text {nom }}$ & $6 \mathrm{~V}$ \\
\hline & $Q_{\text {nom }}$ & $360 \mathrm{Ah}$ \\
\hline & Capital cost & $\$ 300 /$ unit \\
\hline & Replacement cost & $\$ 300 /$ unit \\
\hline & Operation and maintenance cost/year & $\$ 10 /$ unit \\
\hline \multirow[t]{5}{*}{ Converter } & Efficiency & $95 \%$ \\
\hline & Operational lifetime & 15 years \\
\hline & Capital cost & $\$ 0.4 / \mathrm{W}$ \\
\hline & Replacement cost & $\$ 0.4 / W$ \\
\hline & Operation and maintenance cost/year & $\$ 0.01 / W$ \\
\hline
\end{tabular}

\subsection{Results and Discussion}

In this subsection, the performance of the proposed network is critically analyzed in terms of (i) optimal system architecture, (ii) network performance metrics, (iii) energy yield analysis, (iv) cost analysis, and (v) GHG emissions for identifying the key challenges. Moreover, the performance 
parameters of the proposed system are compared with the other system considering the effects of transmission power, system bandwidth, and renewable energy resource profile for ensuring the validity.

\subsubsection{Optimal System Architecture}

The schematic diagrams of the proposed grid-tied hybrid PV/BG system in the HOMER platform are illustrated in Figure $4 \mathrm{a}, \mathrm{b}$ respectively for $P_{T X}=20 \mathrm{~W}$ and $P_{T X}=40 \mathrm{~W}$, while Figure $5 \mathrm{a}, \mathrm{b}$ represents the HOMER layout for an off-grid system. The seasonal DC load profiles of the proposed system for $P_{T X}=20 \mathrm{~W}$ and $P_{T X}=40 \mathrm{~W}$ are respectively shown in Figure 6a,b. In addition, a 30-W lamp is considered as an AC load for the night hours. Tables 6 and 7 summarize the optimal criteria for both on-grid and off-grid systems under $P_{T X}=20 \mathrm{~W}$ and $P_{T X}=40 \mathrm{~W}$. The optimal size of different components has been found considering the average value of solar intensity $\left(4.59 \mathrm{kWh} / \mathrm{m}^{2} /\right.$ day $)$ and average available biomass ( $9 \mathrm{t} /$ day) profile for the selected area. From the numerical data, it is seen that the battery bank capacity and BG size remain unchanged for all configurations, which indicates that the system is reliable. It is also observed that the grid-connected system requires an increased level of converter size in comparison with the off-grid system because grid-connected system has to handle more energy. Moreover, a linear rise of solar PV capacity with the system BW and transmission power is found in order to support the higher load requirement.

Table 6. The optimal architecture of the proposed system for average solar radiation.

\begin{tabular}{ccccccccc}
\hline BW & \multicolumn{2}{c}{ PV $\mathbf{( k W )}$} & \multicolumn{2}{c}{ BG $\mathbf{( k W )}$} & \multicolumn{2}{c}{ Battery (units) } & \multicolumn{2}{c}{ Converter (kW) } \\
\hline $\mathbf{M H z})$ & $\mathbf{2 0} \mathbf{~ W}$ & $\mathbf{4 0} \mathbf{~ W}$ & $\mathbf{2 0} \mathbf{~ W}$ & $\mathbf{4 0} \mathbf{~ W}$ & $\mathbf{2 0} \mathbf{~ W}$ & $\mathbf{4 0} \mathbf{~ W}$ & $\mathbf{2 0} \mathbf{W}$ & $\mathbf{4 0} \mathbf{~ W}$ \\
\hline 5 & 3 & 3.5 & 1 & 1 & 64 & 64 & 1.5 & 1.5 \\
10 & 3 & 3.5 & 1 & 1 & 64 & 64 & 1.5 & 1.5 \\
15 & 3.5 & 4 & 1 & 1 & 64 & 64 & 1.5 & 1.5 \\
20 & 3.5 & 4.5 & 1 & 1 & 64 & 64 & 1.5 & 1.5 \\
\hline
\end{tabular}

Table 7. Summary of technical criteria of the proposed system for different solar intensity, $\mathrm{R}$ $\left(\mathrm{kWh} / \mathrm{m}^{2} /\right.$ day) under $10 \mathrm{MHz}$ bandwidth.

\begin{tabular}{ccccccccc}
\hline $\mathbf{R}$ & \multicolumn{2}{c}{ PV (kW) } & \multicolumn{2}{c}{ BG (kW) } & \multicolumn{2}{c}{ Battery (units) } & \multicolumn{2}{c}{ Converter (kW) } \\
\hline & $\mathbf{2 0} \mathbf{~ W}$ & $\mathbf{4 0} \mathbf{~ W}$ & $\mathbf{2 0} \mathbf{~ W}$ & $\mathbf{4 0} \mathbf{~ W}$ & $\mathbf{2 0} \mathbf{~ W}$ & $\mathbf{4 0 ~} \mathbf{~}$ & $\mathbf{2 0} \mathbf{~ W}$ & $\mathbf{4 0} \mathbf{~ W}$ \\
\hline 4.5 & 3 & 3.5 & 1 & 1 & 64 & 64 & 1.5 & 1.5 \\
5 & 3 & 3.5 & 1 & 1 & 64 & 64 & 1.5 & 1.5 \\
5.5 & 3 & 3.5 & 1 & 1 & 64 & 64 & 1.5 & 1.5 \\
\hline
\end{tabular}

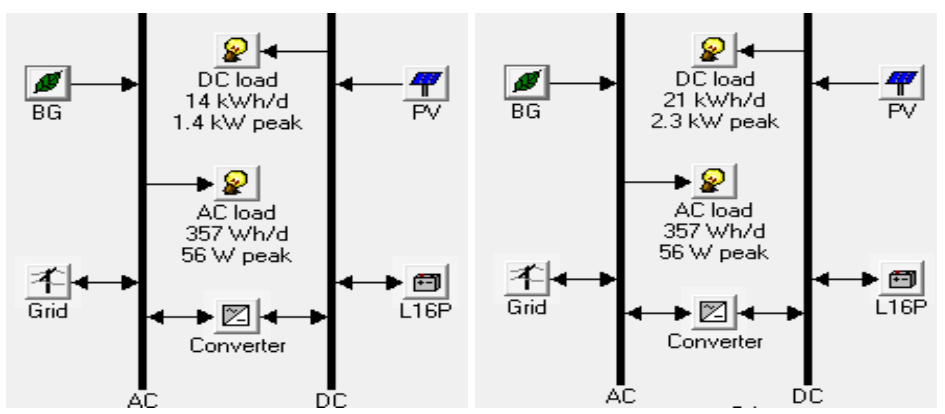

(a) $P_{T X}=20 \mathrm{~W}$

(b) $P_{T X}=40 \mathrm{~W}$

Figure 4. Layout in HOMER for grid-tied macro-BS under BW $=10 \mathrm{MHz}$. 


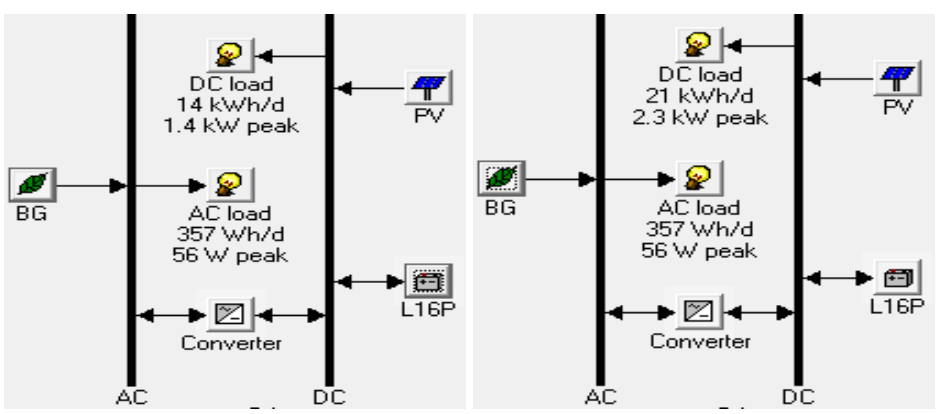

(a) $P_{T X}=20 \mathrm{~W}$

(b) $P_{T X}=40 \mathrm{~W}$

Figure 5. Layout in HOMER for off-grid macro-BS under $B W=10 \mathrm{MHz}$.

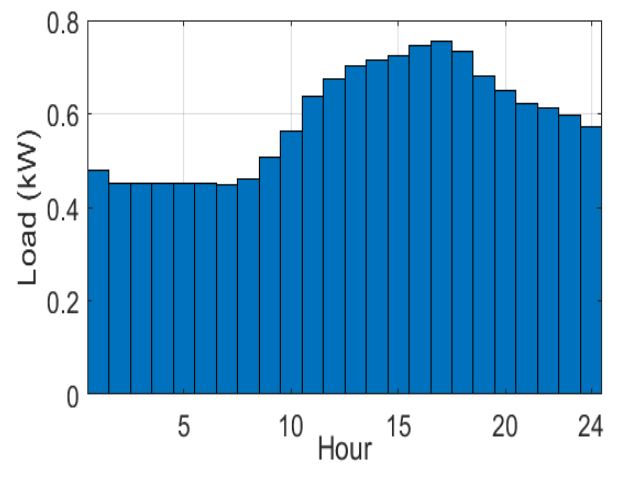

(a) $P_{T X}=20 \mathrm{~W}$

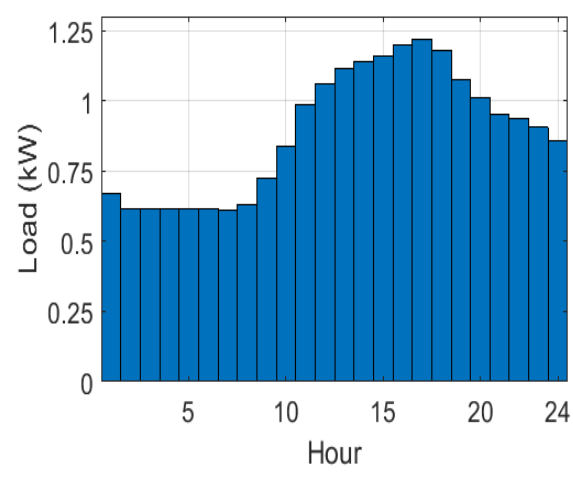

(b) $P_{T X}=40 \mathrm{~W}$

Figure 6. DC load profile for macro-BS under $\mathrm{BW}=10 \mathrm{MHz}$.

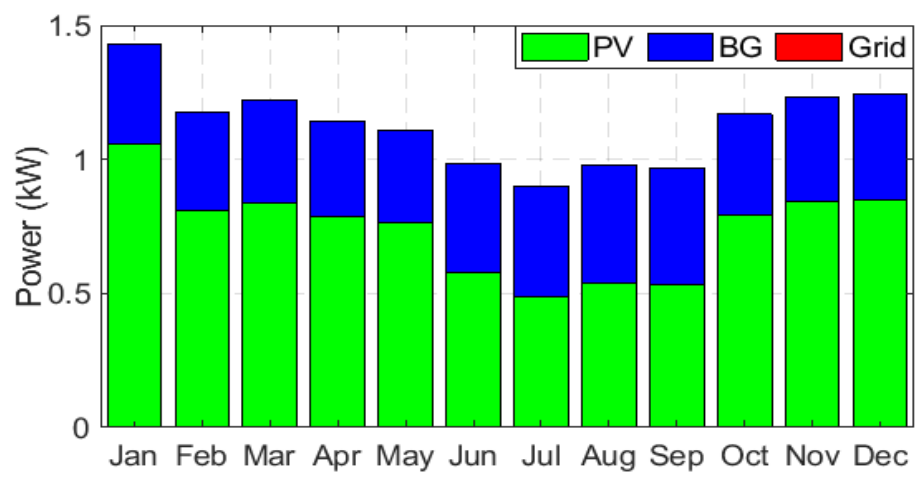

Figure 7. Monthly data of power contribution by on-grid hybrid PV/BG for $P_{T X}=20 \mathrm{~W}$ and $\mathrm{BW}=10 \mathrm{MHz}$.

The complementary effects of solar PV panel and biomass generators for the grid-connected scheme are demonstrated in Figures 7 and 8, whereas Figures 9 and 10 show the monthly statistic of power contribution for the off-grid system. The monthly statistic curve has been found considering the average solar radiation and biomass (rice husk) available under BW $=10 \mathrm{MHz}$. It is also considered that, for a grid-tied system, renewable energy sources supply the BS energy demand without receiving energy from the electrical grid system under normal conditions. All the monthly power contribution curves imply that a significant amount of power was contributed by the solar PV panel due to the higher value of solar radiation profile. It is also noted that the maximum solar PV energy contribution occurs from January to May and November to December when the solar radiation is maximum. Additionally, the minimum PV energy contribution takes place in the months when solar radiation is generally lower due to the rainy season. The rest of the demand is fulfilled by the biomass generator. On the other hand, for the grid-tied system, though the contribution of solar PV energy is a similar image of the yearly solar radiation graph, the contribution of BG is high as compared to the off-grid system. 
Moreover, a higher value of energy generation has been found for a grid-tied system because of selling excess electricity to the grid.

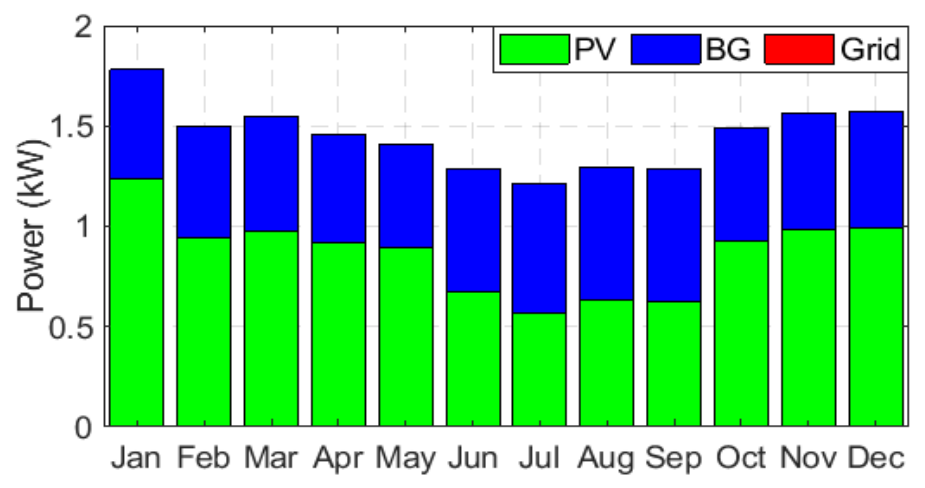

Figure 8. Monthly data of power contribution by on-grid hybrid PV/BG for $P_{T X}=40 \mathrm{~W}$ and $\mathrm{BW}=10 \mathrm{MHz}$.

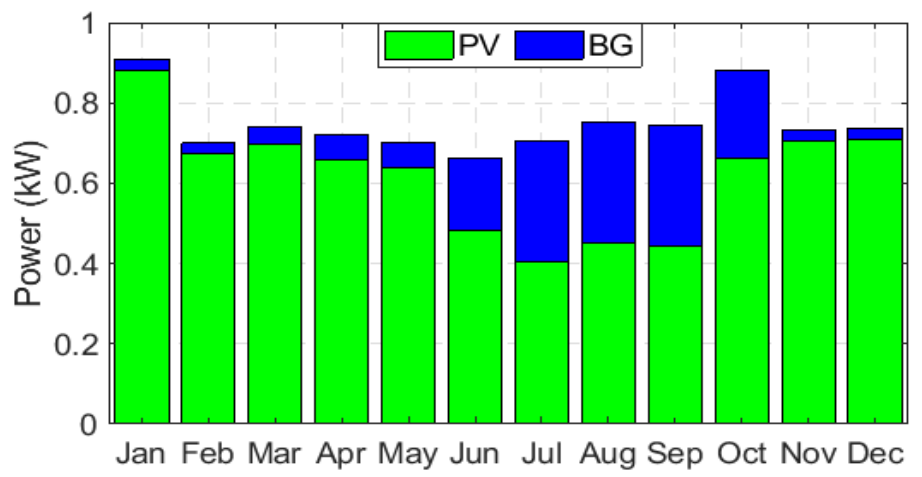

Figure 9. Monthly data of power contribution by off-grid hybrid PV/BG for $P_{T X}=20 \mathrm{~W}$ and $\mathrm{BW}=10 \mathrm{MHz}$.

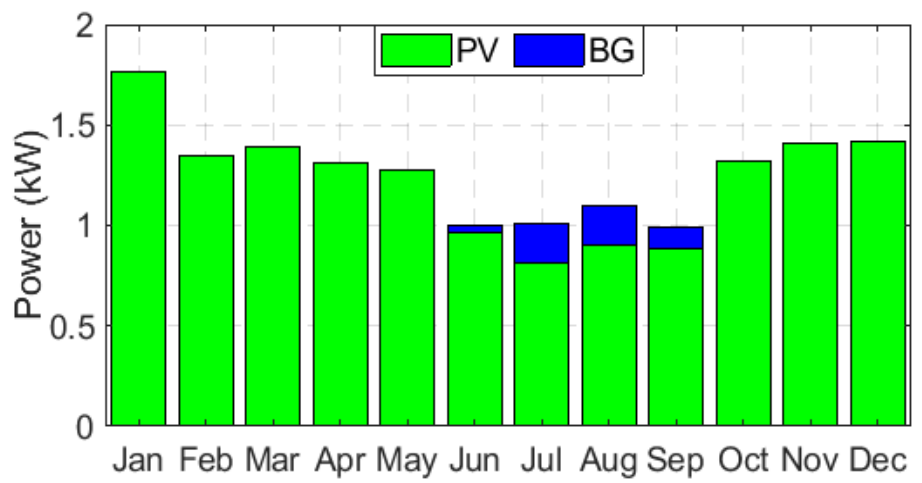

Figure 10. Monthly data of power contribution by off-grid hybrid PV/BG for $P_{T X}=40 \mathrm{~W}$ and $\mathrm{BW}=10 \mathrm{MHz}$.

A clear view of the overall solar PV module size for diverse solar radiation is demonstrated in Figure 11. In line with our expectation, the capacity of the solar PV panel is linearly related to the sunlight intensity for achieving a higher amount of renewable energy selling target. Additionally, the higher transmission power requires higher values of solar PV capacity for most of the cases. 


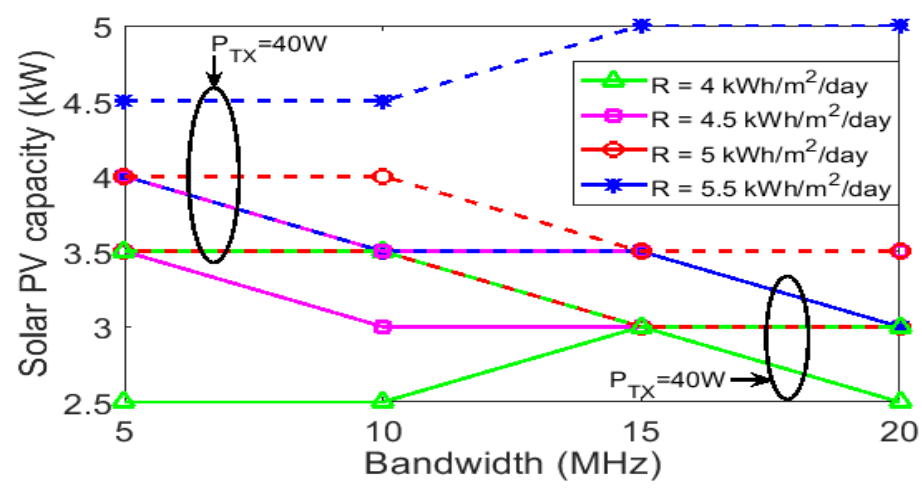

Figure 11. Solar PV panel capacity for the grid-tied hybrid PV/BG system under different solar intensity.

\subsubsection{Network Performance Metrics}

In this subsection, the performance of the wireless network has been critically analyzed in terms of the throughput, spectral efficiency, energy efficiency, and energy efficiency gain matrics considering the temporospatial variation of incoming traffic density as shown in Figure 3. The network has been simulated in the context of 2 tiers, of 19 BSs with hexagonal shape for identifying the inter-cell interference (ICI), and of achieving 4G/5G communications.

Figure 12 illustrates the variation of throughput performance over $24 \mathrm{~h}$ for the introduced network taking ICI into account. Additionally, the throughput performances under different system bandwidth and transmission power are presented in Table 8. A higher value of throughput performance is always desirable, which is a function of resource blocks (RB), and the quantity of RBs is directly retaliated to the traffic profile. For ensuring better performance, it is assumed that each user is linked to at least one $\mathrm{RB}$ and that this number changes with traffic arrival rate. Noticeably, all the throughput curves follow a similar pattern of incoming traffic profile and a significant amount of throughput gap is found between the low density and high density of traffic demand. It is worthy to mention that a large number of RBs is allocated while BSs are run in high BW. Therefore, throughput performance at BW $=20 \mathrm{MHz}$ reveals an optimistic nature compared to others as evident from Table 8. It is also remarkable that the throughput performances for $P_{T X}=20 \mathrm{~W}$ and $P_{T X}=40 \mathrm{~W}$ are very insignificant. This is due to the fact that ICI power increases simultaneously with the received signal power, resulting in consistent throughput performance. The spectral efficiency (SE) comparison of the considered mobile network under different BW is summarized in Table 8. As a matter of fact, SE mainly depends on throughput and system BW.

Table 8. Throughput and spectral efficiency performance of the wireless network.

\begin{tabular}{ccccccccc}
\hline & \multicolumn{3}{c}{ Throughput (Kbps) } & \multicolumn{3}{c}{ Spectral Efficiency (Kbps/Hz) } \\
\cline { 2 - 9 } BW (MHz) & \multicolumn{2}{c}{ On-Grid } & \multicolumn{2}{c}{ Off-Grid } & \multicolumn{2}{c}{ On-Grid } & \multicolumn{2}{c}{ Off-Grid } \\
\cline { 2 - 9 } & $\mathbf{2 0 ~ W}$ & $\mathbf{4 0 ~ W}$ & $\mathbf{2 0 ~ W}$ & $\mathbf{4 0 ~ W}$ & $\mathbf{2 0 ~ W}$ & $\mathbf{4 0 ~ W}$ & $\mathbf{2 0 ~ W}$ & $\mathbf{4 0 ~ W}$ \\
\hline 5 & 46,651 & 46,531 & 46,651 & 46,531 & $9.33 \times 10^{-3}$ & $9.30 \times 10^{-3}$ & $9.33 \times 10^{-3}$ & $9.30 \times 10^{-3}$ \\
10 & 95,421 & 100,128 & 95,421 & 100,128 & $9.54 \times 10^{-3}$ & $9.50 \times 10^{-3}$ & $9.54 \times 10^{-3}$ & $9.50 \times 10^{-3}$ \\
15 & 147,917 & 146,253 & 147,917 & 146,253 & $9.86 \times 10^{-3}$ & $9.65 \times 10^{-3}$ & $9.86 \times 10^{-3}$ & $9.65 \times 10^{-3}$ \\
20 & 194,582 & 198,759 & 194,582 & 198,759 & $9.72 \times 10^{-3}$ & $9.93 \times 10^{-3}$ & $9.72 \times 10^{-3}$ & $9.93 \times 10^{-3}$ \\
\hline
\end{tabular}




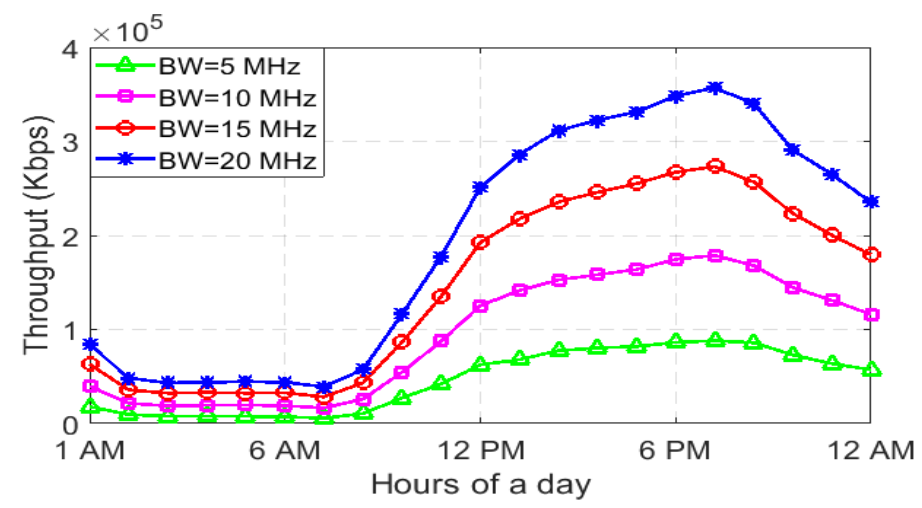

Figure 12. A quantitative comparison of throughput performance under different system bandwidth.

The energy-efficient and energy efficiency gain metrics of the proposed network in consideration with the realistic traffic pattern are respectively depicted in Figures 13 and 14. According to Equations (22) and (23), a higher value of throughput and a lower value of power consumption have a positive impact on EE performance. Moreover, throughput performance is directly related to the RBs, and higher system BW uses more RBs. In contrast, higher system BW and transmission power are liable to increasing the net power consumption. As a consequence, a better energy efficiency performance can be achieved by running the suggested network at $P_{T X}=20 \mathrm{~W}$ and $\mathrm{BW}=10 \mathrm{MHz}$. On the other hand, energy efficiency gain measures the improvement of energy efficiency performance by the selected hybrid PV/BG enabled network compared to the reference off-grid hybrid PV/BG enabled system. To the end, Figure 14 implies that the proposed network can attain EE improvement by about $20 \%$ with effective modeling of the hybrid PV/BG system.

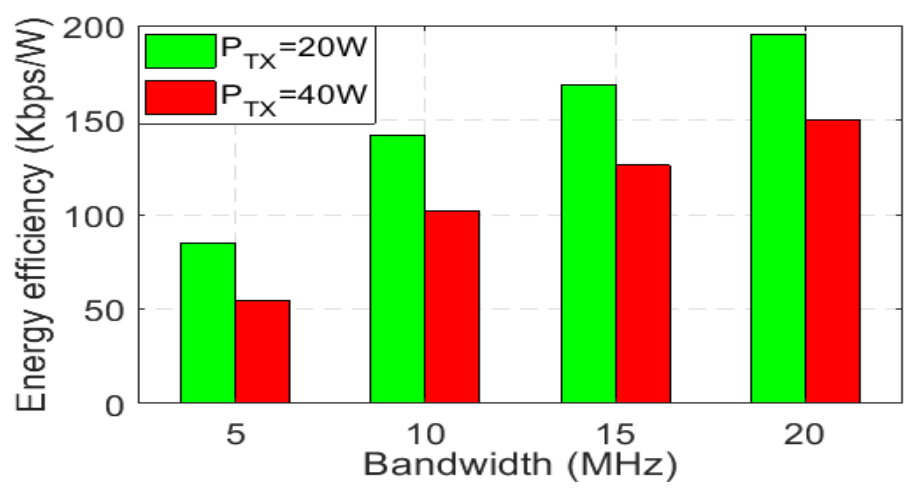

Figure 13. A quantitative comparison of EE performance under different system bandwidth.

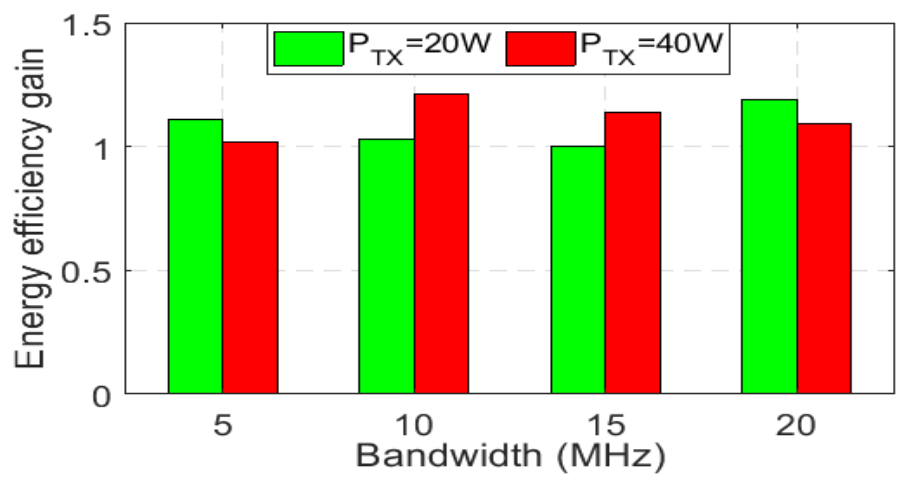

Figure 14. A quantitative comparison of EE gain performance under different system bandwidth. 


\subsubsection{Energy Yield Analysis}

In this section, the annual energy generated by the solar PV panel, BG, amount of excess electricity, and sold energy are critically analyzed based on the optimal design criteria. Moreover, the battery lifespan, battery bank autonomy, and bio-feedstock consumption have been thoroughly investigated under different network configurations. Figure 15 illustrates the energy consumption ratio of different loads for the grid-connected system, where the amount of sold energy to the grid has been considered as load. This figure indicates that, with the increment of transmitted power, DC load consumption by base station has increased from $61 \%$ to $72 \%$. Hence, grid sales have decreased from $37 \%$ to $27 \%$.
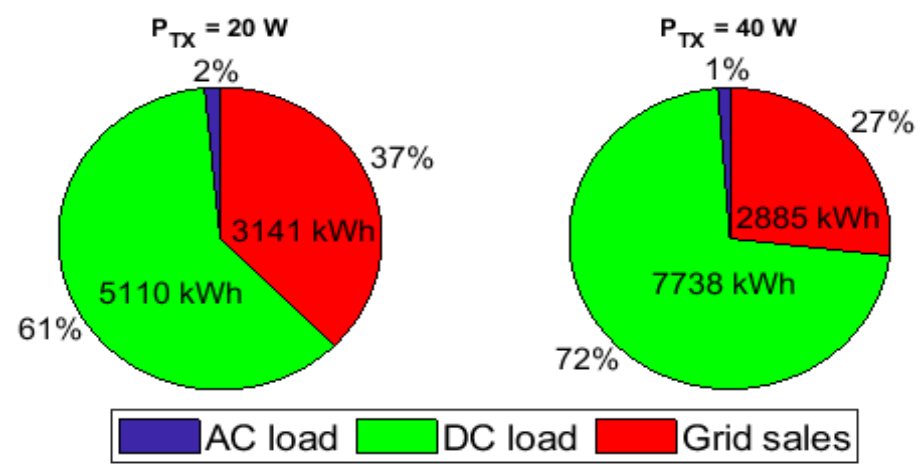

Figure 15. Energy breakdown for the grid-tied hybrid PV/BG system under BW $=10 \mathrm{MHz}$.

\section{Solar PV Panel}

The optimal size of the solar PV panel required for the hybrid PV/BG system is summarized in Tables 6 and 7. With reference to the tables for $P_{T X}=20 \mathrm{~W}$ and $\mathrm{BW}=10 \mathrm{MHz}$, the proposed scheme consists of 12 (i.e., $3 \mathrm{~kW}$ ) Sharp ND-250QCs solar modules: 4 connected in series and 3 connected in parallel to be compatible with the requirements of the charge controller. On the other hand, the proposed system consists of 14 (i.e., $3.5 \mathrm{~kW}$ ) Sharp ND-250QCs solar modules for $P_{T X}=40 \mathrm{~W}$ and $\mathrm{BW}=10 \mathrm{MHz}$, which is calculated by Equation (2): $N_{P V}=\frac{P_{p}}{P_{\max }}=\frac{3.5 \mathrm{~kW}}{250 \mathrm{~W}}=14$. Focusing on the characteristic curve, the Sharp ND-250QC solar module is a good choice for this work.

The total amount of energy generated by the solar PV panel for $P_{T X}=20 \mathrm{~W}$ and $\mathrm{BW}=10 \mathrm{MHz}$ can be evaluated using Equation (1): $E_{P V}=3 \mathrm{~kW}\left(R_{P V}\right) \times 4.59(P S H) \times 0.9\left(\eta_{P V}\right) \times 365$ days/year $=$ $4523.45 \mathrm{kWh} /$ year. Moreover, a two-axis tracking mode of solar PV panel enhances the solar energy generation by $43.4 \%$, resulting in the production of $6486 \mathrm{kWh} /$ year. In a similar process, energy generated for all other configurations is calculated. The yearly energy produced by the set of solar PV panels for dissimilar network arrangement is presented in Figure 16 considering the average solar radiation profile. All the curves like Figure 11 are showing escalation, which indicates that higher system BW and $P_{T X}$ contribute to the higher yearly energy impact. Due to cost optimization, there is no fixed trend of solar energy generation for the on-grid and off-grid systems. In most of the cases of the off-grid system, the energy generations by the solar PV panel are higher due to the reservation of higher excess energy. 


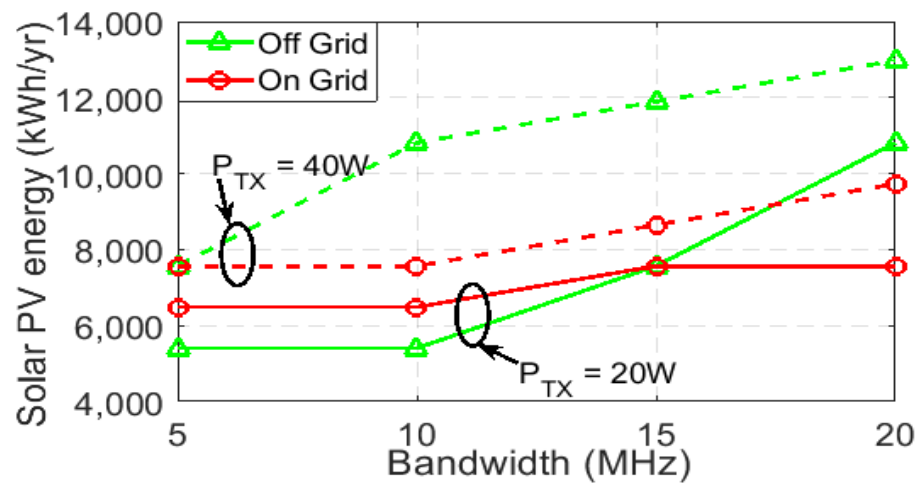

Figure 16. Solar energy generation for the proposed system under different bandwidth.

\section{Biomass Generator}

According to the Tables 6 and 7, the optimal size of the biomass generator for all configurations is $1 \mathrm{~kW}$. The amount of power produced and the corresponding yearly energy generated by the BG can be found by the Equations (3) and (4) in the following way: $P_{B G}=3.49 \mathrm{t} /$ year $\left(T_{B M}\right) 3411.33 \mathrm{KCal} / \mathrm{Kg}$ $\left(C V_{B M}\right) \times 0.30\left(\eta_{B G}\right) \times 1000 /\left(365 \times 860 \times 11.38 \mathrm{~h}\left(t_{o p}\right)\right)=0.999 \mathrm{~kW}$ and $E_{B G}=0.999 \mathrm{~kW}\left(P_{B G}\right) \times 365$ $\times 24 \times 0.389$ (capacity factor) $=3406 \mathrm{kWh} /$ year for macro BS, under average biomass available.

A quantitative comparison of bio-feedstock consumption with respect to the system BW under different grid conditions is presented in Figure 17. Additionally, Figure 18 signifies the effect of the biomass generator running hours on the BG lifespan. From the figures, it is found that a greater value of BG running time increases the consumption of bio-feedstock lowering the BG lifetime. Figure 17 also depicts that a grid-tied system with $P_{T X}=40 \mathrm{~W}$ consumes more biomass than the off-grid system owing to the increased load demand by selling energy to the grid. The energy generated by the biomass generator is a similar pattern of bio-feedstock consumption as shown in Figure 19. However, a lower value of BG functioning time upturns the BG lifetime and enhances the system performance by a substantial reduction of $\mathrm{CO}_{2}$ emissions. On the other hand, a greater value of $\mathrm{BG}$ functioning time specifies the higher yearly energy contributions by the biomass generator, which improves the system reliability and grid capacity by maximum utilization of locally available renewable energy sources.

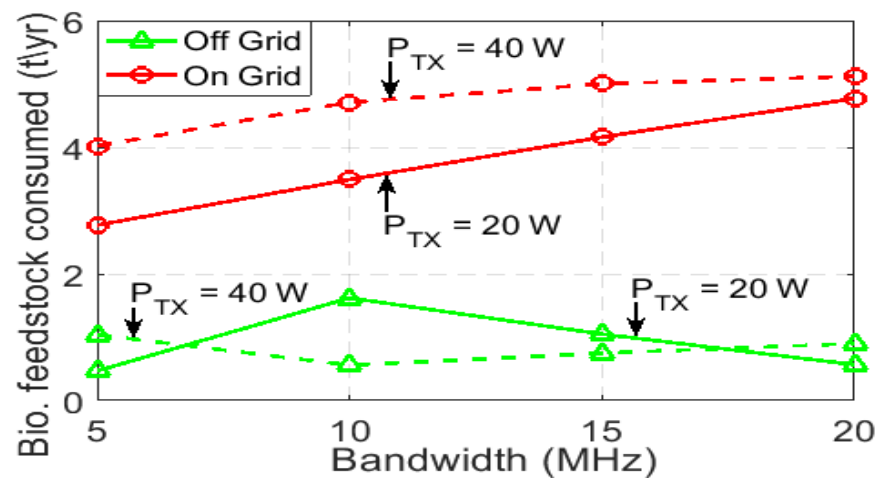

Figure 17. Bio-feedstock consumed for the proposed system under different bandwidth. 


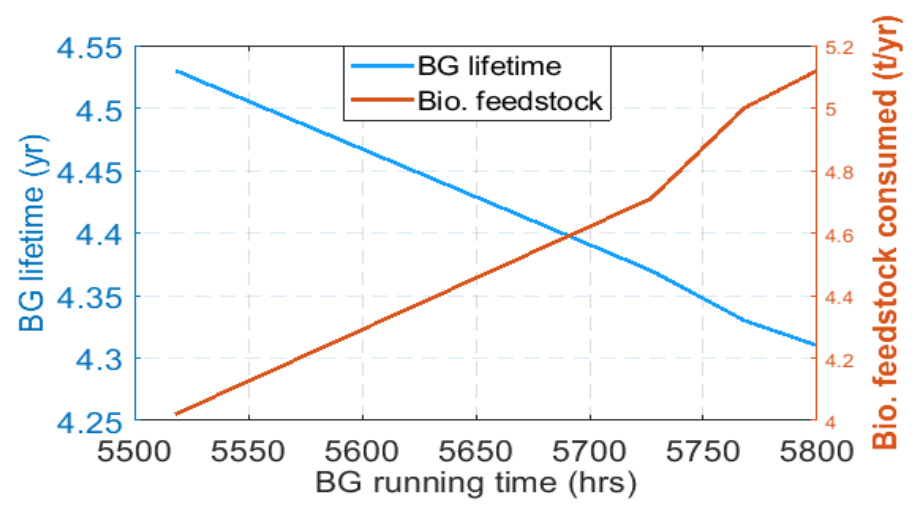

Figure 18. BG life and Bio-feedstock consumed for the proposed system with BG operating hours.

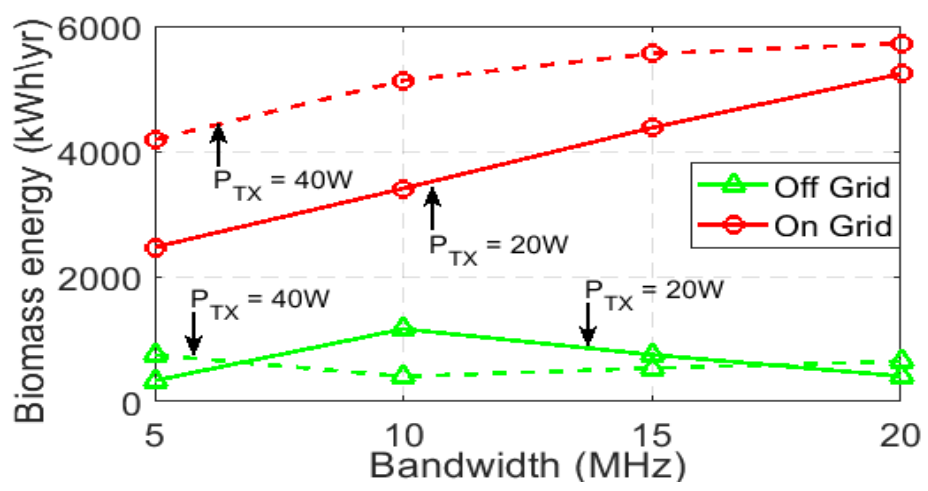

Figure 19. Energy generated by the BG for the proposed system under different bandwidth.

Energy Breakdown

HOMER optimization software determines the generated energy (from solar PV and BG), compares it with the different types of demand such as electrical load (base station DC and AC load) and losses (battery and converter loss), and take decisions at each step about how to manage the excess electricity in terms of charging battery and selling to the grid. For $\mathrm{BW}=10 \mathrm{MHz}$ and $P_{T X}=20 \mathrm{~W}$, HOMER calculates the excess energy using Equation (17) as follows: $E_{\text {Excess }}=6486 \mathrm{kWh}$ $\left(E_{P V}\right)+3406 \mathrm{kWh}\left(E_{B G}\right)-5240 \mathrm{kWh}\left(E_{B S}\right)-3141 \mathrm{kWh}\left(E_{\text {sales }}\right)-16 \mathrm{kWh}\left(B_{\text {loss }}\right)-493 \mathrm{kWh}\left(C_{\text {loss }}\right)=$ $1002 \mathrm{kWh} /$ year. By the analogous process, the annual excess electricity generated for another network setting can be determined.

The annual energy breakdown for both on-grid and off-grid systems are respectively summarized in Figures 20 and 21. The data presented in these figures have been found considering the average solar/biomass profile in the context of different transmission power and system BW. As is seen, the grid-tied system consists of a significant amount of excess electricity, which implies that the system can meet the BS load requirement independently. From the energy breakdown curves, it is also observed that the grid-tied system has the provision to transfer a higher amount of energy to the grid, which enhances the system reliability by maximizing the utilization of renewable energy sources and by maintaining zero energy shortage. A higher value of excess electricity is always desirable for ensuring better performance. Figure 20 and 21 clearly depict that the proposed system has sufficient excess electricity for all configurations. Finally, a greater amount of excess electricity is found for the higher value of the $P_{T X}$. 


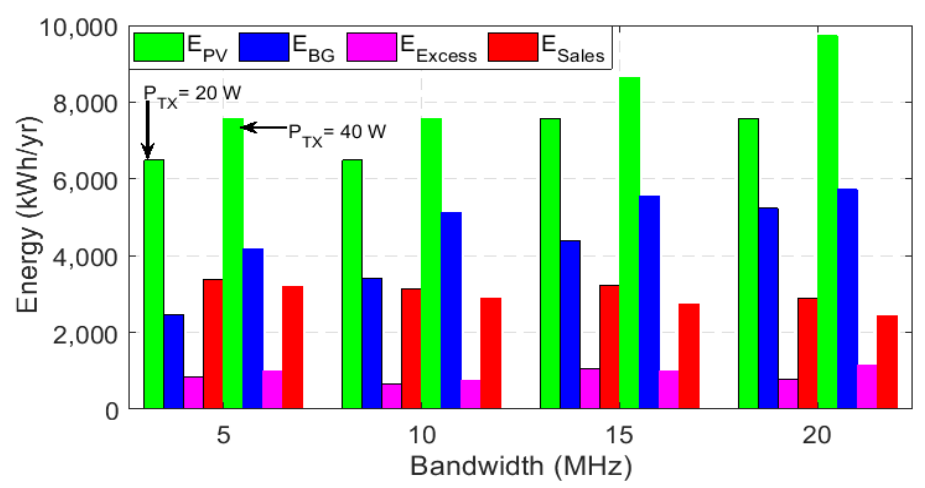

Figure 20. Annual energy breakdown for the grid-tied hybrid PV/BG system.

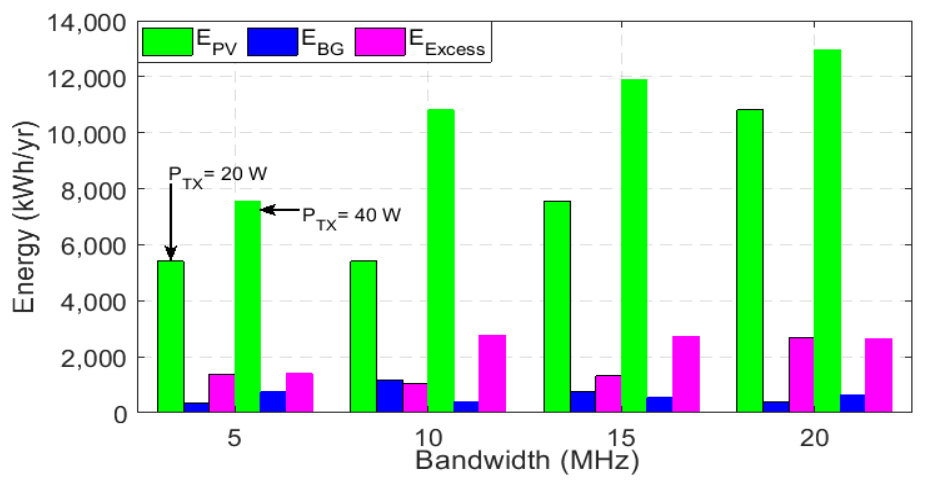

Figure 21. Annual energy breakdown for the off-grid hybrid PV/BG system.

The monthly statistics of sold energy by the energy selling facility to the grid is shown in Figure 22, while Figure 23 represents a clear picture of the transferred electricity under various system BW and transmission power. It is noteworthy that a significant amount of green energy can be transferred to the grid throughout the year after fulfilling the BS's own energy demand. In the end, the grid-tied system has a positive impact on the public utility grid as well as the reduction of fossil fuel, which can substantially minimize $\mathrm{CO}_{2}$.

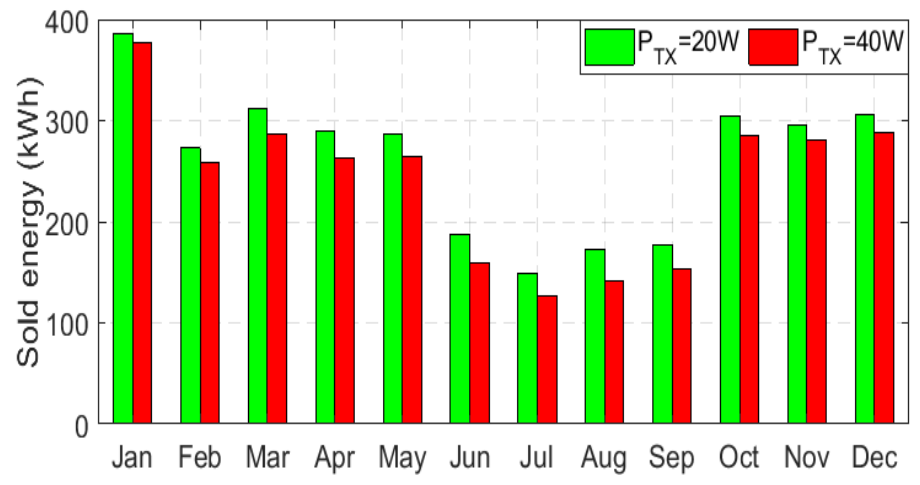

Figure 22. Monthly sold energy for the grid-tied hybrid PV/BG system. 


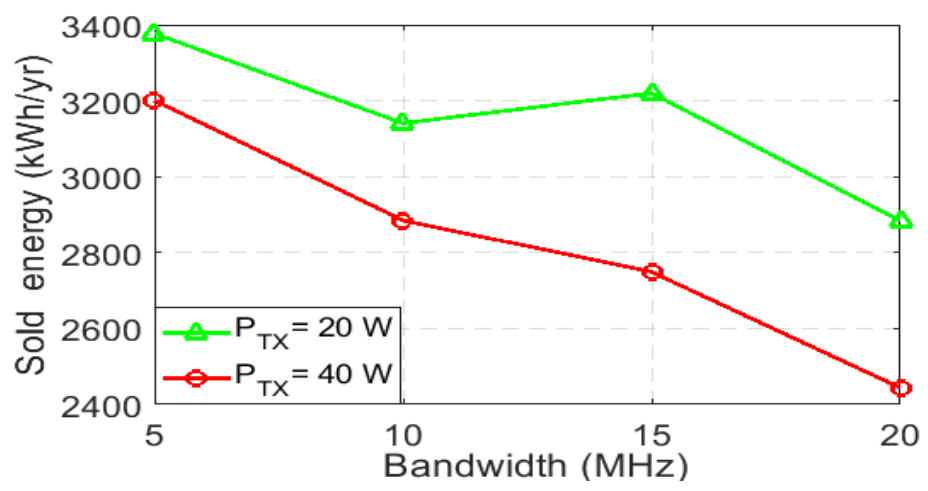

Figure 23. Sold energy for the grid-tied hybrid PV/BG system under different BW.

Battery Bank

The total number of battery units that are required for both $P_{T X}=20 \mathrm{~W}$ and $P_{T X}=40 \mathrm{~W}$ of the proposed configuration is 64: 8 connected in series and 8 in parallel to be compatible with the 48-V DC bus bar. The storage device provides backup power for $162 \mathrm{~h}$, which is determined using Equation (7) for $P_{T X}=20 \mathrm{~W}, \mathrm{BW}=10 \mathrm{MHz}$, and $R_{\text {avg }}$ configuration: $B_{\text {aut }}=64\left(N_{\text {batt }}\right) \times 6 \mathrm{~V}\left(V_{\text {nom }}\right) \times 360 \mathrm{Ah}\left(Q_{\text {nom }}\right)$ $\times 0.7\left(B_{D O D}\right) \times 24 \mathrm{~h} /$ daily load, $L_{B S}=14.93 \mathrm{kWh}=162 \mathrm{~h}$. The autonomy of the battery bank for other configurations can also be determined by the analogous process. Additionally, lifetime $\left(B_{\text {life }}\right)$ and annual throughput $\left(Q_{t h p}\right)$ of the storage device can be calculated using Equation (8).

Figure 24 represents the battery bank autonomy $\left(B_{a u t}\right)$ for both off-grid and on-grid systems under different system bandwidth and transmission power. The values of $B_{a u t}$ for off-grid and the on-grid systems are identical in both systems as the number of battery units is the same. However, it gradually decreases with the system bandwidth as the daily BS load consumption increases correspondingly. If any BS has to be upgraded from off-grid to an on-grid system, then no major battery backup system has to be changed. Other feasibility calculations can also be done easily. A greater value of $B_{a u t}$ is preferable for designing sustainable system architecture to fulfill the BS demand for an elongated period of time. Improved performance of battery lifetime naturally reduces the replacement price, decreasing the overall net present cost.

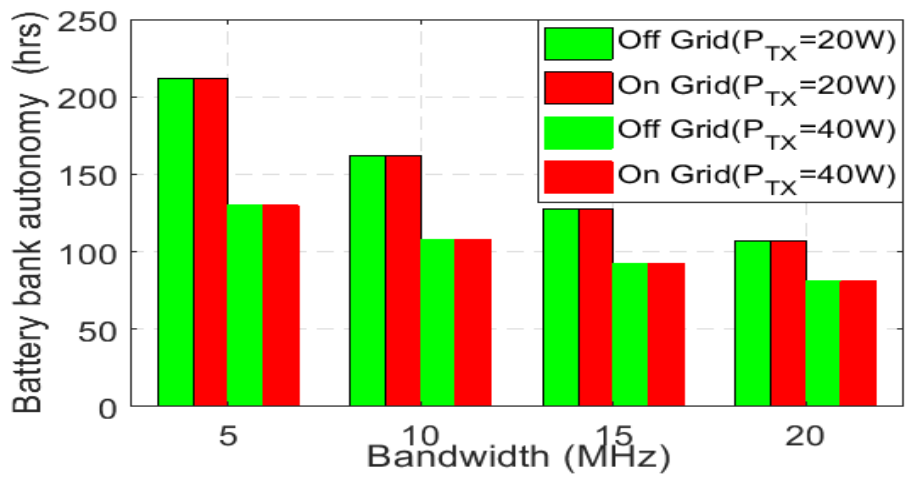

Figure 24. Battery bank autonomy vs. bandwidth. 


\subsubsection{Cost Analysis}

In this subsection, the economic feasibility of the proposed hybrid PV/BG scheme has been critically analyzed in terms of capital cost (CC), replacement cost (RC), operation and maintenance cost (OMC), salvage value (SV), fuel cost (FC), and total net present cost (NPC) that have to be maintained within the project duration. The cost breakdown of the individual components is performed considering the average renewable energy availability of the selected area.

The nominal cash flow summary of the hybrid PV/BG system in the HOMER platform for the grid-tied system under $\mathrm{BW}=10 \mathrm{MHz}$ and $P_{T X}=20 \mathrm{~W}$ is demonstrated in Figure 25. The total NPC contains all types of costs that are necessary during the project lifetime and determined in each year of the project as follows: Capital cost $\$ 23,460+$ Replacement cost $\$ 11,542+$ OMC $\$ 3668+$ Fuel cost $\$ 1130$ - Salvage value $\$ 379$, which equals $\$ 39,421$. As is seen, the highest amount of cost is the capital cost, which is required at the beginning of the project, whereas replacement cost is the second-highest due to the smaller lifecycle of BG, battery, and converter. Additionally, a bulk amount of OMC and FC is included because of the continuous maintenance and biomass requirement, which uplifts the total NPC of the project. The leftover cost of each unit at the termination of the project period is counted as salvage value, which is indicated in the figure as negative.

On the other hand, the individual cost breakdown for the off-grid system keeping the grid system aside is shown in Figure 26. All the systems have a significant amount of CC and OMC. The total number of the battery unit and the cost of battery per unit are the key factors for increasing the CC and OMC of the scheme. It is seen that an off-grid system without an energy-selling facility handles smaller energy as compared to the grid-tied system. An off-grid system also requires a smaller amount of biomass and converter size. As a consequence, the off-grid system has a decreased level of CC, RC, and FC though the NPC is high. It is also remarkable that a large amount of price will be paid back by selling the excess renewable energy to the public utility grid. In the end, the grid-tied system consists of a negative OMC, which represents the return of money, substantially reducing total NPC and cost of electricity. For more clarification, a short summary of the sale-back price under different transmission power and BW is presented in Figure 27.

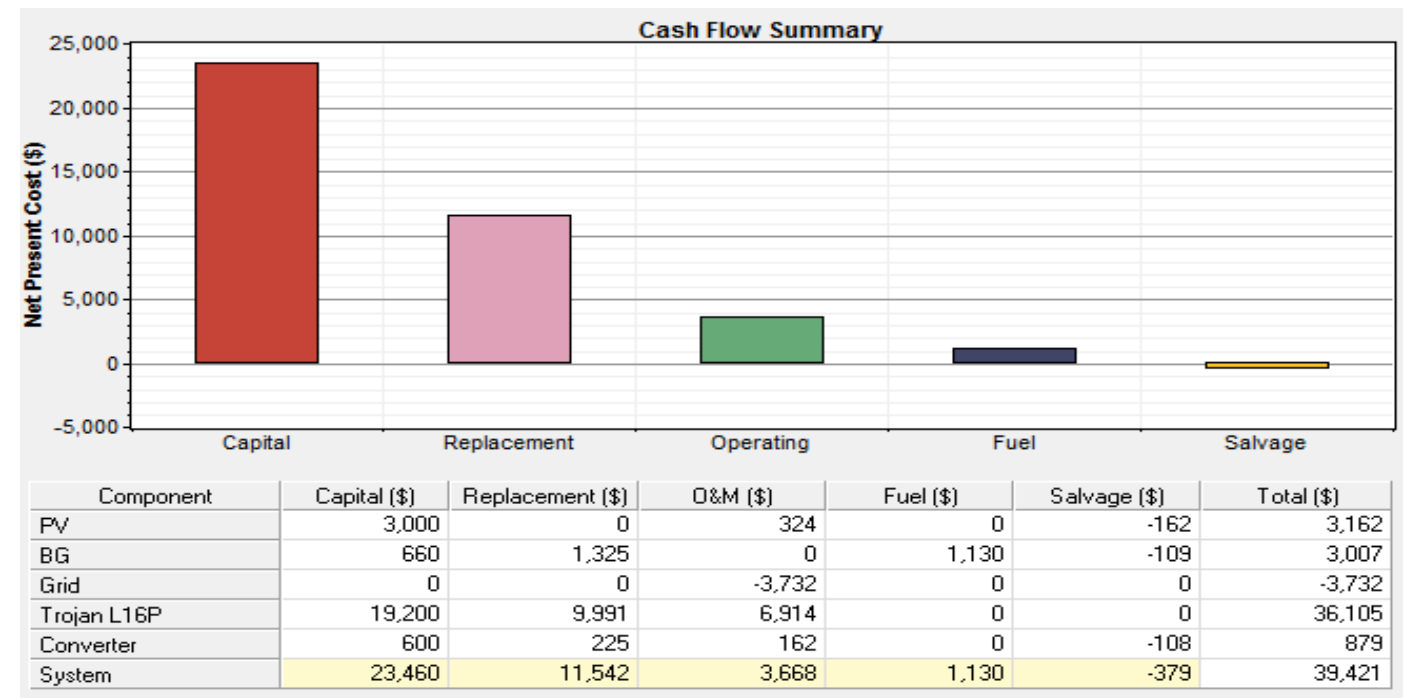

Figure 25. Cash flow summary for the grid-tied hybrid PV/BG system under $10 \mathrm{MHz}$ bandwidth. 


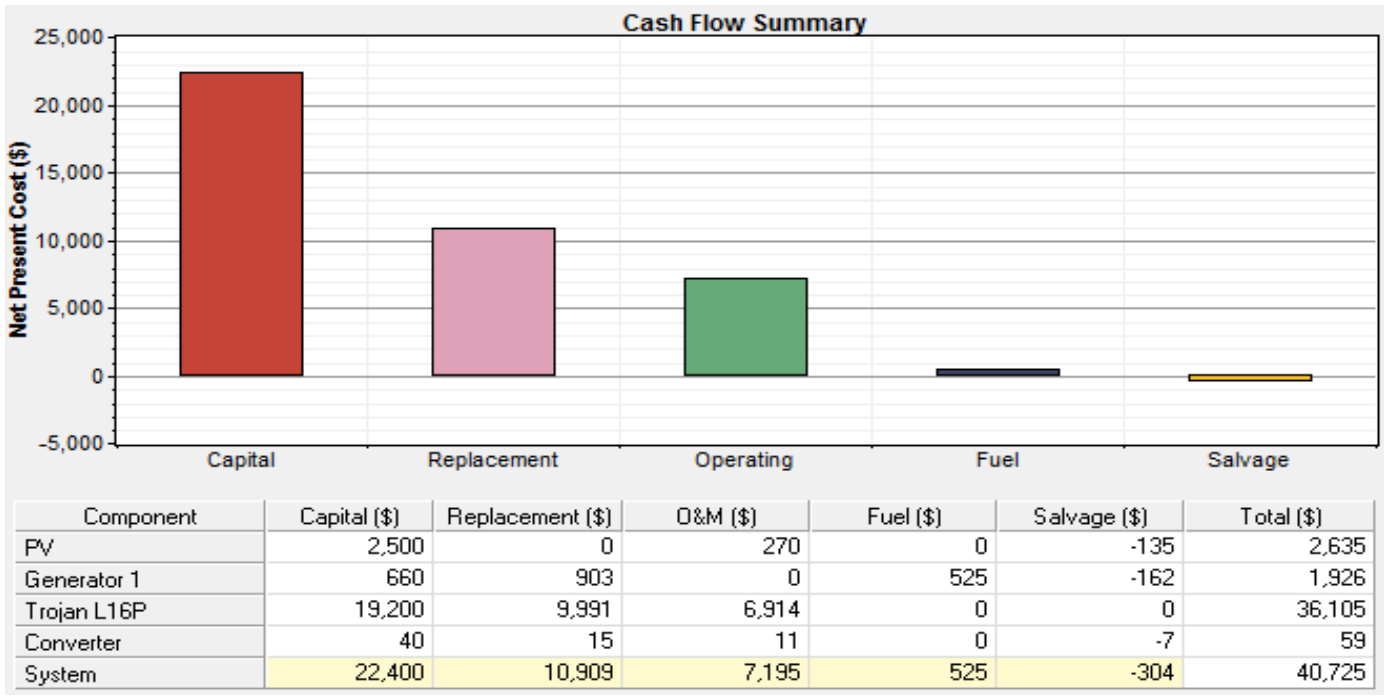

Figure 26. Cash flow summary for the off-grid hybrid PV/BG system under $10 \mathrm{MHz}$ bandwidth.

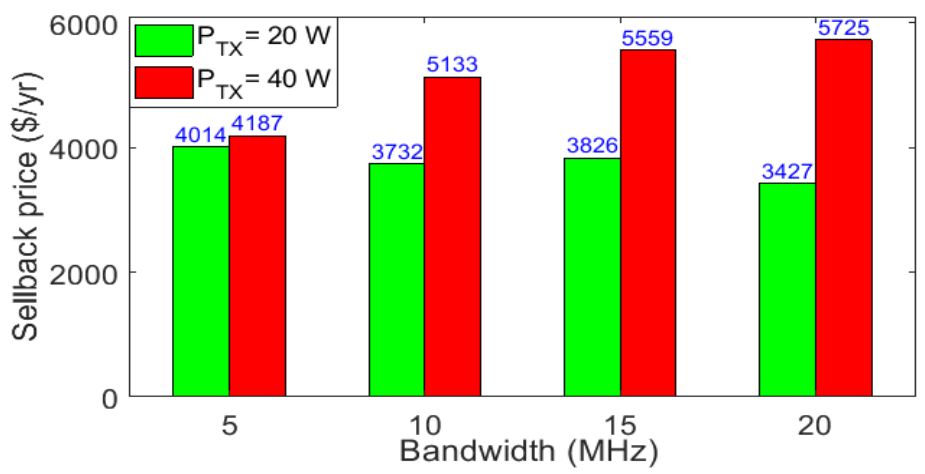

Figure 27. Sellback price for the grid-tied hybrid PV/BG system under different BW.

The individual cost breakdown of the entire project for various system bandwidth and solar intensity is respectively summarized in Tables 9 and 10. In line with our expectation, a gradual increment of CC, RC, OMC, FC, and NPC is found for a greater value of system bandwidth and transmission power to cope up with the higher energy demand. Moreover, the capital expense is inversely related to solar radiation as shown in Table 10.

Table 9. Cost breakdown of the proposed system under various system BW.

\begin{tabular}{|c|c|c|c|c|c|c|c|c|c|c|c|c|}
\hline BW & \multicolumn{2}{|c|}{ CC (\$) } & \multicolumn{2}{|c|}{ RC (\$) } & \multicolumn{2}{|c|}{ OMC (\$) } & \multicolumn{2}{|c|}{ FC (\$) } & \multicolumn{2}{|c|}{ SV (\$) } & \multicolumn{2}{|c|}{ NPC (\$) } \\
\hline (MHz) & $20 \mathrm{~W}$ & $40 \mathrm{~W}$ & $20 \mathrm{~W}$ & $40 \mathrm{~W}$ & $20 \mathrm{~W}$ & $40 \mathrm{~W}$ & $20 \mathrm{~W}$ & $40 \mathrm{~W}$ & $20 \mathrm{~W}$ & $40 \mathrm{~W}$ & $20 \mathrm{~W}$ & $40 \mathrm{~W}$ \\
\hline 5 & 23,460 & 23,960 & 11.479 & 11,546 & 3937 & 4246 & 897 & 1303 & 436 & 403 & 39,377 & 40,653 \\
\hline 10 & 23,460 & 23,960 & 11,542 & 11,577 & 3668 & 4644 & 1130 & 1525 & 379 & 373 & 39,421 & 41,334 \\
\hline 15 & 23,960 & 24,460 & 11,550 & 11,583 & 4226 & 4864 & 1347 & 1621 & 399 & 394 & 40,683 & 42,135 \\
\hline 20 & 23,960 & 24,460 & 11,575 & 11,583 & 4646 & 5285 & 1548 & 1660 & 373 & 416 & 41,353 & 43,077 \\
\hline
\end{tabular}

Table 10. Cost breakdown of the proposed system under various solar intensity, $\mathrm{R}\left(\mathrm{kWh} / \mathrm{m}^{2} /\right.$ day $)$.

\begin{tabular}{ccccccccccccc}
\hline $\mathbf{R}$ & \multicolumn{2}{c}{ CC (\$) } & \multicolumn{2}{c}{ RC (\$) } & \multicolumn{2}{c}{ OMC (\$) } & \multicolumn{2}{c}{ FC (\$) } & \multicolumn{2}{c}{ SV (\$) } & \multicolumn{2}{c}{ NPC (\$) } \\
\hline & $\mathbf{2 0} \mathbf{W}$ & $\mathbf{4 0} \mathbf{W}$ & $\mathbf{2 0} \mathbf{W}$ & $\mathbf{4 0} \mathbf{W}$ & $\mathbf{2 0} \mathbf{W}$ & $\mathbf{4 0} \mathbf{W}$ & $\mathbf{2 0} \mathbf{W}$ & $\mathbf{4 0} \mathbf{W}$ & $\mathbf{2 0} \mathbf{W}$ & $\mathbf{4 0} \mathbf{W}$ & $\mathbf{2 0} \mathbf{W}$ & $\mathbf{4 0} \mathbf{~ W}$ \\
\hline 4.5 & 23,460 & 23,960 & 11,545 & 11,583 & 3965 & 4749 & 1135 & 1535 & 377 & 367 & 39,528 & 41,460 \\
5 & 23,460 & 23,960 & 11,523 & 11,558 & 3293 & 4227 & 1108 & 1490 & 397 & 391 & 38,987 & 40,844 \\
5.5 & 23,460 & 23,960 & 11,501 & 11,536 & 2928 & 3814 & 1048 & 1455 & 416 & 412 & 38,557 & 40,352 \\
\hline
\end{tabular}


Figure 28 depicts the clear image of the net present cost for both on-grid and off-grid macro-BS varying the system $\mathrm{BW}$ and $P_{T X}$. The graph tells that higher $\mathrm{BW}$ and $P_{T X}$ incurs greater NPC likewise Table 9. According to Equation (11), the BS energy demand goes to the upper direction to support the higher system BW and $P_{T X}$, and hence, NPC curves follow a similar pattern. It is also observed that the off-grid curves lie above the on-grid curves, so the grid-tied hybrid solar PV/BG system is more cost-effective. In addition, the impact of biomass price on the total net present cost is illustrated in Figure 29 under different network configurations. As is expected, all the NPC curves show an increasing trend with respect to the biomass price. This is happening because the biomass price is linearly related to the fuel cost as well as NPC.

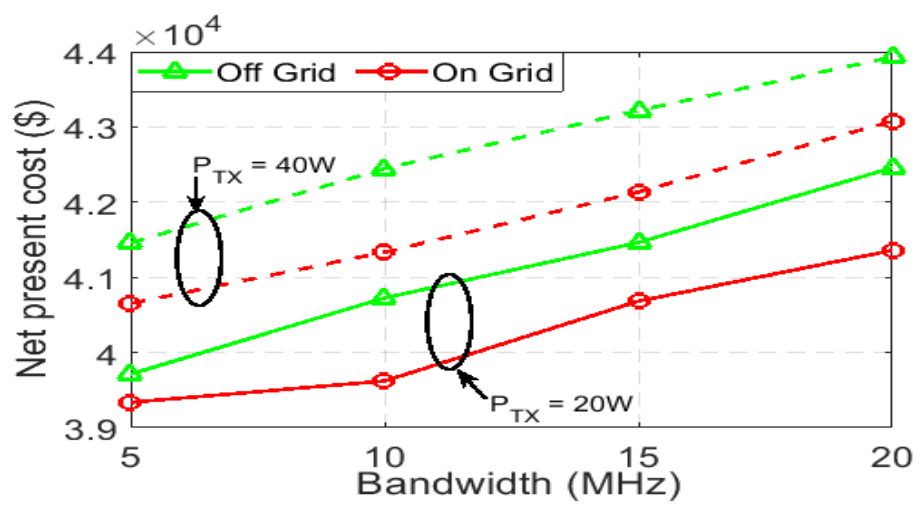

Figure 28. Net present cost vs. bandwidth for the proposed system.

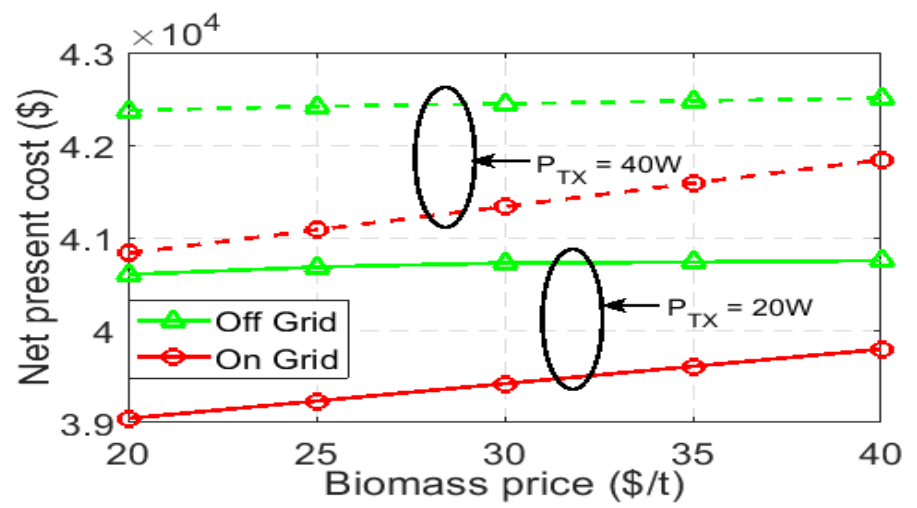

Figure 29. Net present cost vs. biomass price for the proposed system.

The effect of $P_{T X}$ and BW variation on the cost of electricity is shown in Figure 30 for both off-grid and on-grid conditions. The electricity generation cost as well as the per-unit cost of electricity is gradually falling with the increment of system $\mathrm{BW}$ and $P_{T X}$. It is happening because of the higher amount of electricity generation, resulting in the decrement in total expenses. From the aforementioned analysis, it is concluded that a better value of $\mathrm{COE}$ can be obtained by installing the BS at higher system BW and higher transmission power. Additionally, the COE curves under different transmission power can be explored by varying the biomass price as shown in Figure 31. It is noticed that lower transmission power and higher biomass price are responsible for poor economic performance. 


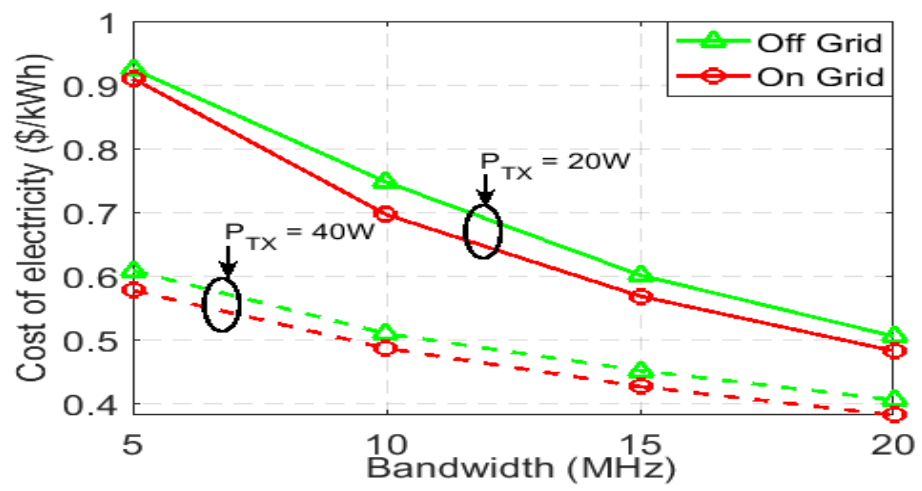

Figure 30. Cost of electricity vs. bandwidth for the proposed system.

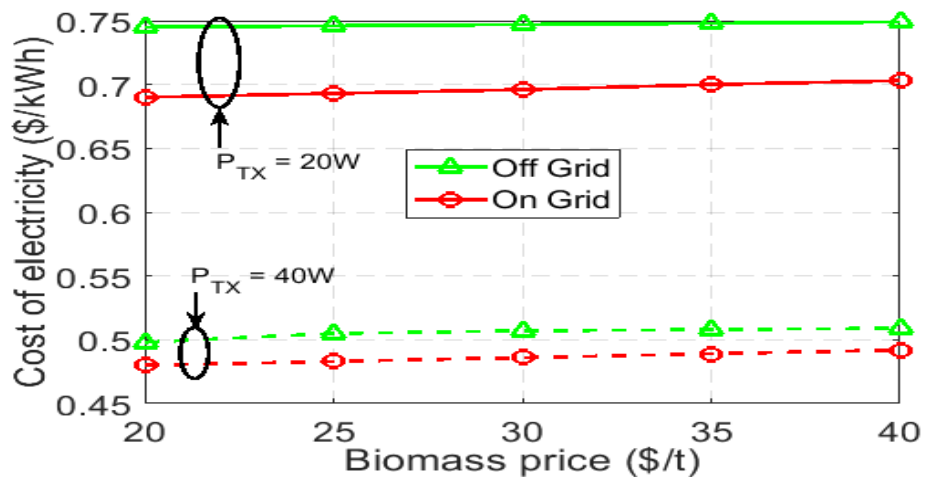

Figure 31. Cost of electricity vs. biomass price for the proposed system.

\subsubsection{GHG Emissions}

Solar is an ideal renewable energy source that emits zero carbon content. Moreover, the higher volume carbon footprint of biomass generators can be kept at a lower level due to technological advancement. An extensive comparison of greenhouse gas emissions for the off-grid and on-grid configurations of solar PV/BG is shown in Figure 32. The figure depicts that the GHG emission is close to zero for the off-grid system. However, it will show a slight surge with the increment of $P_{T X}$ and BW. On the other hand, the grid-tied arrangement of the hybrid solar PV/BG system exhibits negative emissions because of transferring a greater amount of excess electricity to the grid. This transfer of green energy will directly reduce the GHG emissions of the fossil fuel-based grid system. Finally, the proposed system can indirectly reduce the carbon contents by minimizing the burning of fossil fuel and biomass.

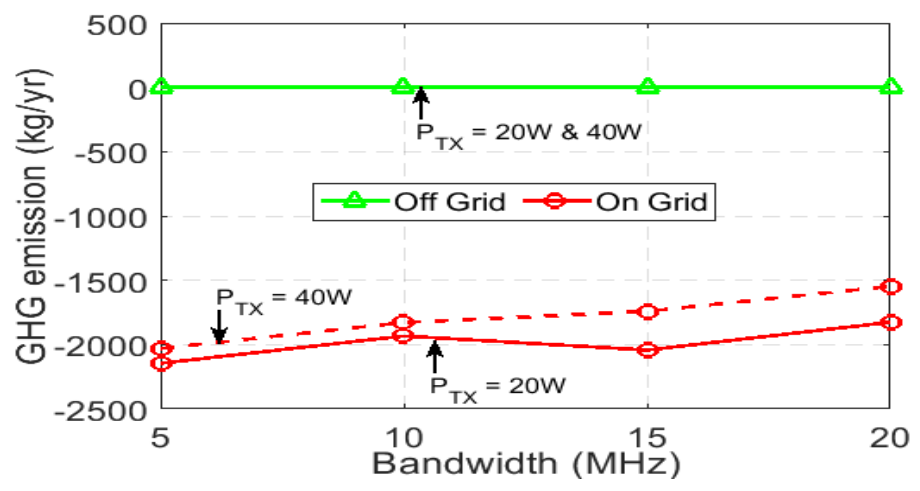

Figure 32. Greenhouse gas emissions vs. biomass price for the proposed system. 


\subsection{Feasibility Comparison}

In this subsection, the performance parameters of the proposed hybrid PV/BG system are compared with the standalone solar PV, hybrid PV/WT, and hybrid PV/DG for ensuring the validity. For presenting a clear view, different power providing schemes have been simulated under the same network setting considering the average solar intensity and biomass profile. A quantitative comparison of technical criteria including the optimal size is summarized in Table 11 for the aforementioned supply system that is obtained from the HOMER software. As is seen, the optimal architecture of the proposed system is in a feasible range and remains almost close to the other supply schemes, which ensure the effectiveness of the system. Noticeably, a large number of solar PV panels are required in order to satisfy the BS energy demand for both standalone solar PV and hybrid PV/DG-powered systems, leading to a remarkable enhancement in NPC and COE.

Table 11. Summary of technical criteria for the different scheme under $P_{T X}=20 \mathrm{~W}$ and $\mathrm{BW}=10 \mathrm{MHz}$.

\begin{tabular}{ccccccccccc}
\hline $\begin{array}{c}\text { Supply } \\
\text { Scheme }\end{array}$ & $\begin{array}{c}\mathbf{P V} \\
\mathbf{( k W )}\end{array}$ & $\begin{array}{c}\text { BG } \\
\mathbf{( k W )}\end{array}$ & $\begin{array}{c}\text { DG } \\
\mathbf{( k W )}\end{array}$ & $\begin{array}{c}\mathbf{W T} \\
\mathbf{( k W )}\end{array}$ & $\begin{array}{c}\text { Conv. } \\
\mathbf{( k W )}\end{array}$ & $\begin{array}{c}\boldsymbol{N}_{\text {batt }} \\
\mathbf{( U n i t s )}\end{array}$ & $\begin{array}{c}\boldsymbol{B}_{\text {loss }} \\
\mathbf{( k W h / y e a r )}\end{array}$ & $\begin{array}{c}\boldsymbol{B}_{\text {aut }} \\
\mathbf{( h )}\end{array}$ & $\begin{array}{c}\boldsymbol{C}_{\text {loss }} \\
\mathbf{( k W h} / \text { year) }\end{array}$ & $\begin{array}{c}E_{\text {Excess }} \\
\mathbf{( k W h / y e a r )}\end{array}$ \\
\hline $\mathrm{PV}$ & 2.5 & $*$ & $*$ & $*$ & 0.1 & 64 & 463 & 162 & 14 & 1949 \\
$\mathrm{PV} / \mathrm{WT}$ & 1 & $*$ & $*$ & 1 & 0.1 & 64 & 164 & 162 & 14 & 878 \\
$\mathrm{PV} / \mathrm{DG}$ & 4 & $*$ & 1 & $*$ & 0.1 & 64 & 476 & 162 & 14 & 2911 \\
$\mathrm{PV} / \mathrm{BG}$ & 3 & 1 & $*$ & $*$ & 1.5 & 64 & 16 & 162 & 493 & 1002 \\
\hline \multicolumn{8}{c}{$*$ Not applicable. }
\end{tabular}

A detailed comparison of the cost of electricity under different supply schemes is illustrated in Figures 33 and 34 along with the variation of system bandwidth and transmission power. It is observed that the COE curves are in the lower position for the grid-tied system, which implies that the grid-connected hybrid PV/BG scheme attains optimistic results wherein standalone solar PV exhibits average results. In line with our expectation, the hybrid PV/DG scheme provides poor value and hybrid PV/WT represents superior performance. Though results show the best output for the hybrid $\mathrm{PV} / \mathrm{WT}$ system configuration, this hybrid system is not feasible because of the complicacy of the WT setup and low-speed wind graph in the selected location. On the other hand, the hybrid PV/BG system provides greater reliability compared to the standalone solar PV system because the single energy technology source solar energy generation may be outage depending on the weather condition. As a consequence, the hybrid PV/BG system is an attractive solution for powering the macro-BS.

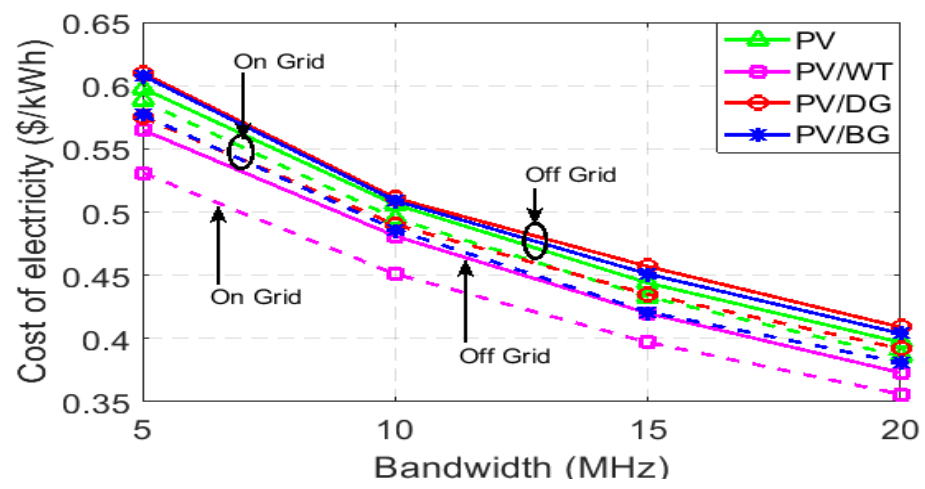

Figure 33. Comparison of COE between on-grid and off-grid under different system BW. 


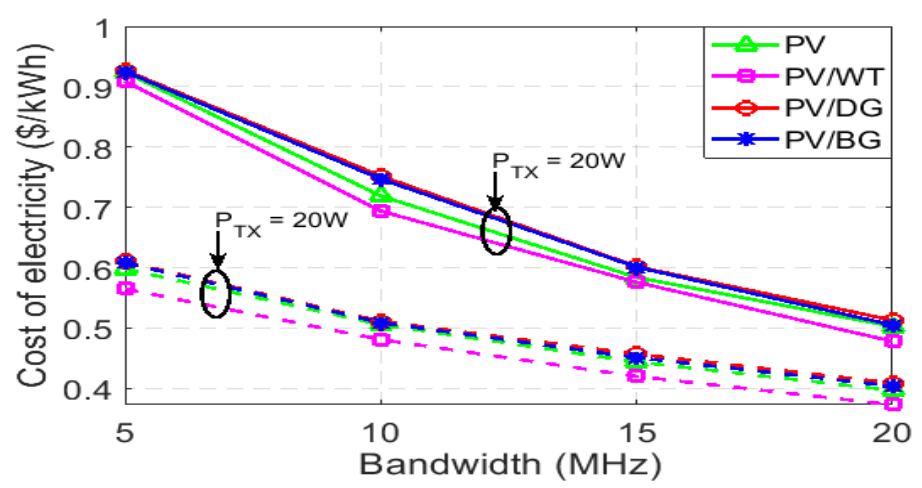

Figure 34. Comparison of COE under different transmission power.

Figures 35 and 36 compare the net present cost among the various supply system likewise in the events discussed in the COE comparison section. It is found that hybrid PV/WT and standalone solar PV involve lower NPC for all cases, whereas the hybrid PV/BG exhibits a medium level of NPC. At the same time, the hybrid PV/DG provides poor NPC because of the continuous requirement of a higher amount of OMC and fuel cost. However, the grid-tied hybrid PV/BG has better NPC performance due to the unavailability of the required wind speed.

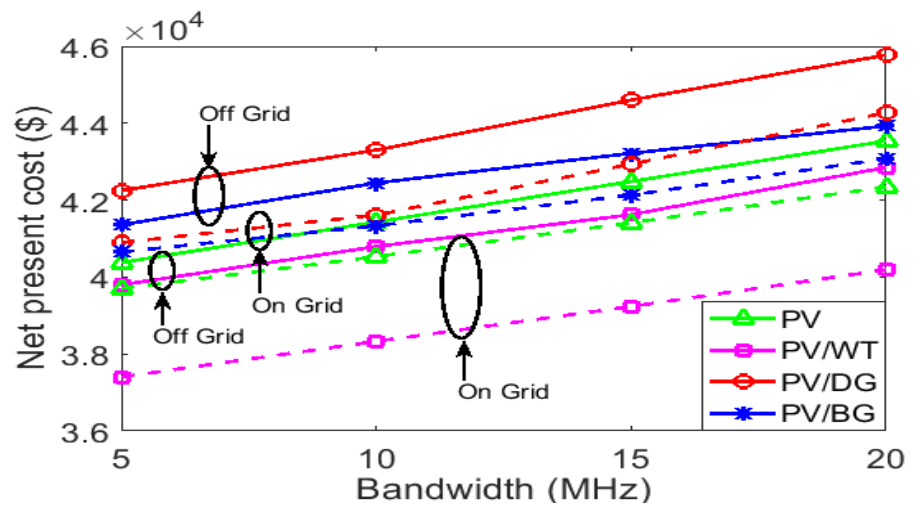

Figure 35. Comparison of NPC between on-grid and off-grid under different system BW.

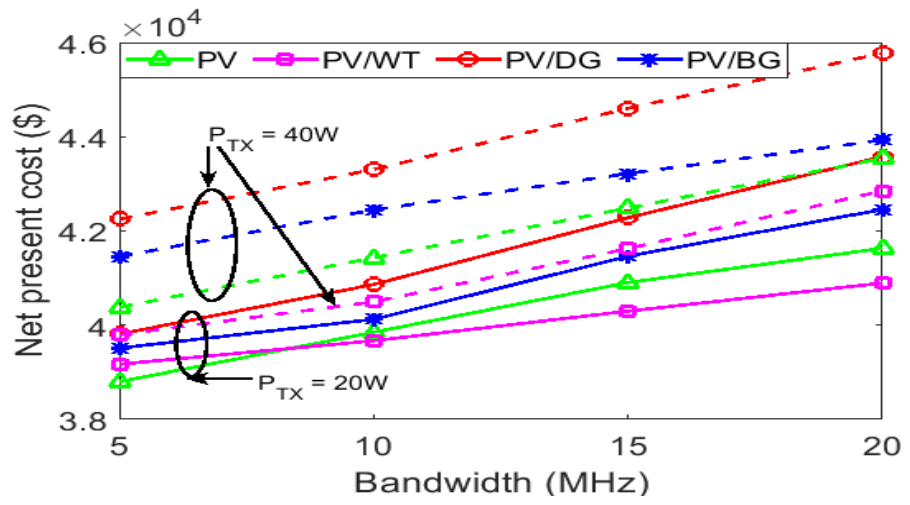

Figure 36. Comparison of NPC under different transmission power.

A quantitative comparison of energy efficiency performance among the different supply systems taking the effect of dynamic traffic profile into accounts is demonstrated in Figures 37 and 38. These two graphs illustrate that the hybrid PV/BG scheme provides a satisfactory level of EE performance as compared to the hybrid PV/DG and hybrid PV/WT system. It is also observed that the standalone solar PV provides superior EE performance than the other supply schemes due to the smaller amount 
of losses and excess electricity. Finally, the lower system BW and transmission power uplift the EE performance of the system under all cases.

An extensive comparison of carbon footprints among the aforementioned supply schemes is illustrated in Figure 39. It is remarkable that solar PV and hybrid PV/WT do not contain any carbon contents whereas hybrid PV/BG emits a negligible amount of greenhouse gas. On the other hand, hybrid PV/DG produces a huge amount of GHG due to the burning of a large amount of diesel during the entire project. It is also seen that hybrid PV/DG consumes more fossil fuel to cope up with higher system BW and contributes a greater amount of carbon pollutants. Though the hybrid solar PV/BG system emits a small amount of GHG, environmental degradation can be decreased by reducing the use of biomass in the cooking process.

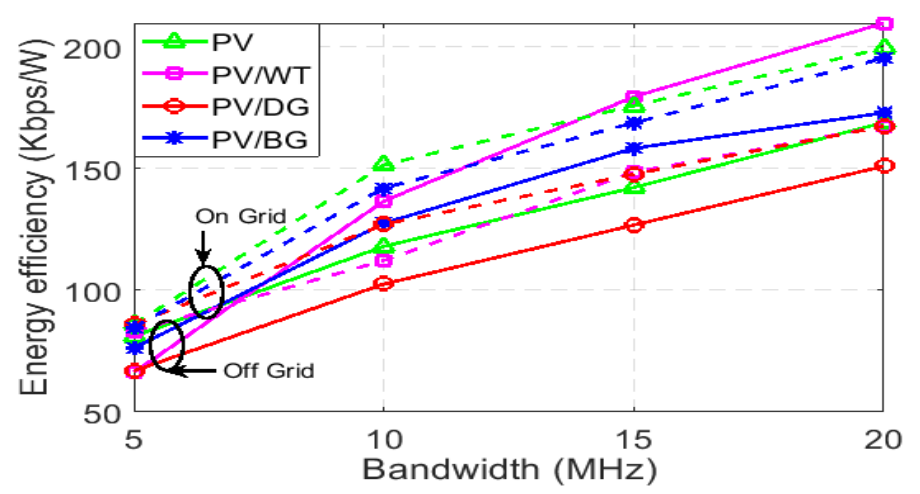

Figure 37. Energy efficiency performance comparison among the PV, PV/DG, PV/WT, and PV/BG.

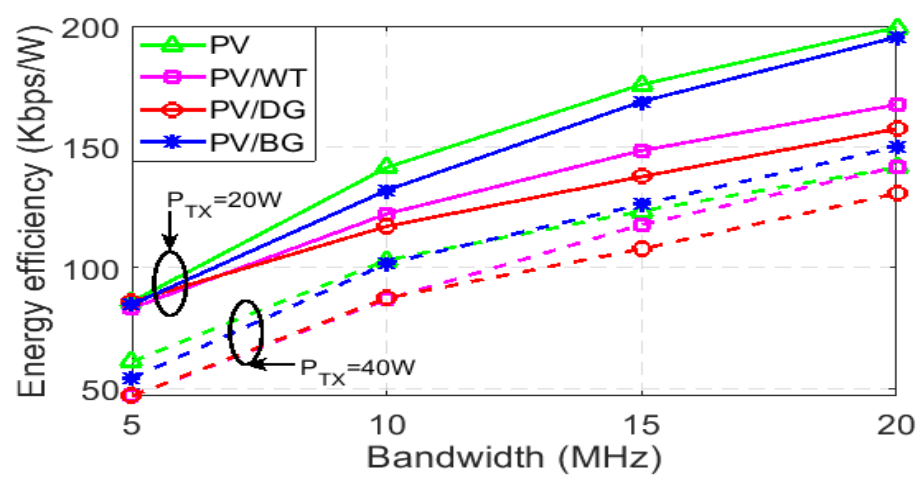

Figure 38. Energy efficiency comparison performance among the PV, PV/DG, PV/WT, and PV/BG.

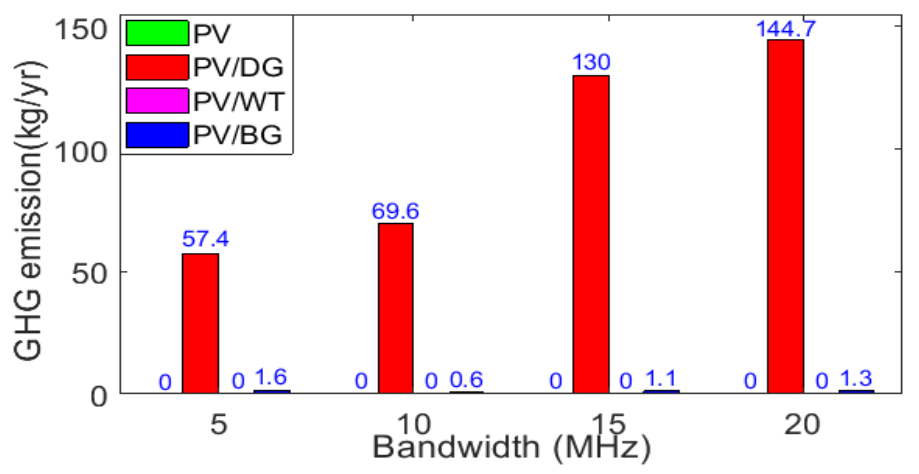

Figure 39. Comparison of greenhouse gases (GHG) among the PV, PV/DG, PV/WT, and PV/BG. 


\subsection{Limitation Analysis}

The major limitations of the hybrid solar PV/BG system are summarized below.

- The installation of the hybrid solar PV/BG system requires a large amount of biomass, land, and water, which are not widely available throughout the world to cope with the demand fully by energy-hungry equipment.

- Energy harvesting from biomass involves a small amount of greenhouse gas emissions, though a higher volume of carbon contents can be maintained at a lower value with the help of technological advancement.

- The unreliable nature of renewable energy production is a major challenge while designing a large-scale cellular infrastructure. Thus, the installation of the hybrid solar PV/BG system requires a significant number of battery units. Therefore, there may be a loss of load probability due to the older age of the battery bank, and it involves a greater maintenance and replacement cost as well.

\section{Conclusions}

This paper examines the feasibility of deploying a combined solar PV and biomass-focused sustainable supply system for powering the LTE macro-base stations in order to reduce both net present cost and carbon contents. The sensitivity of the suggested system has been evaluated using the HOMER software in terms of optimal architecture, energy production, capital cost, and pollution rate varying system parameters such as transmission power and system bandwidth. The outcomes of the simulation depict that the hybrid solar PV/BG system can independently support the BS energy requirement without sacrificing the quality of services. The battery bank and grid system can provide sufficient backup power which explicitly conforms to the reliability issue. Additionally, the proposed system has the ability to transfer around $3141 \mathrm{kWh}$ energy per year to the grid, keeping an additional $10 \%$ of exploited energy to the respective BS itself for ensuring further plausibility. Numerical results also demonstrate the robustness of grid-tied hybrid PV/BG system that achieved NPC and COE saving up to $3.20 \%$ and $6.82 \%$, respectively, compared to the off-grid system. Moreover, the performance of the wireless network has been evaluated in terms of throughput, spectral efficiency, and energy efficiency metrics. A significant improvement of energy efficiency can be achieved and a considerable amount of carbon content can be saved if the off-grid hybrid PV / BG system is replaced by the grid-tied system. It is revealed that the proposed system performs a lot better than the hybrid solar PV/DG. It has also achieved better reliability as compared to the solar PV system. In summary, the hybrid solar PV/BG-powered cellular networks with an energy-selling facility to the grid is an effective way of developing an energy-efficient green mobile communication with affordable cost.

Author Contributions: Conceptualization, M.S.H.; methodology, A.J.; software, M.S.H. and A.J.; Data curation, M.S.H. and K.Z.I.; Formal analysis, K.Z.I.; Investigation, M.H.A.; Visualization, M.S.H., A.J. and K.Z.I.; Writing-original draft, M.S.H. and K.Z.I.; Writing-review and editing, A.J. and M.H.A.; Supervision, M.F.R. All authors have read and agreed to the published version of the manuscript.

Funding: This research received no external funding.

Conflicts of Interest: The authors declare no conflicts of interest.

\section{References}

1. Ericsson. Mobile Subscriptions First Quarter 2019. Available online: https://wwwricsson.com/en/mobilityreport/reports/june-2019/mobile-subscriptions-q1-2019 (accessed on 10 January 2020).

2. Alsharif, M.; Kelechi, A.; Kim, J.; Kim, J. Energy efficiency and coverage trade-off in 5G for eco-friendly and sustainable cellular networks. Symmetry 2019, 11, 408. [CrossRef]

3. GSMA. Country Overview: Bangladesh. Available online: https://www.gsmaintelligence.com/research/ ?file=a163eddca009553979bcdfb8fd5f2ef0\&download (accessed on 10 January 2020).

4. Alsharif, M.H. Techno-economic evaluation of a stand-alone power system based on solar power/batteries for global system for mobile communications base stations. Energies 2017, 10, 392. [CrossRef] 
5. Aris, A.; Shabani, B. Sustainable power supply solutions for off-grid base stations. Energies 2015, 8, 10904-10941. [CrossRef]

6. World Energy Outlook 2018. Available online: https://wwwea.org/weo2018/ (accessed on 10 January 2020).

7. Jahid, A.; Hossain, M.S.; Monju, M.K.H.; Rahman, M.F.; Hossain, M.F. Techno-economic and energy efficiency analysis of optimal power supply solutions for green cellular base stations. IEEE Access 2020, 8, 43776-43795. [CrossRef]

8. Alsharif, M.H.; Nordin, R.; Abdullah, N.F.; Kelechi, A.H. How to make key 5G wireless technologies environmental friendly: A review. Trans. Emerg. Telecommun. Technol. 2017, 29, 1-32. [CrossRef]

9. Jahid, A.; Hossain, M.S. Feasibility analysis of solar powered base stations for sustainable heterogeneous networks. In Proceedings of the IEEE Region 10 Humanitarian Technology Conference (R10-HTC), Dhaka, Bangladesh, 21-23 December 2017; pp. 686-690.

10. Hasan, Z.; Boostanimehr, H.; Bhargava, V.K. Green cellular networks: a survey, some research issues and challenges. IEEE Commun. Surv. Tutor. 2011, 13, 524-540. [CrossRef]

11. Jahid, A.; Hossain, M.S. Energy-cost aware hybrid power system for off-grid base stations under green cellular networks. In Proceedings of the IEEE International Conference on Electrical Information and Communication Technology (EICT), Khulna, Bangladesh, 7-9 December 2017; pp. 1-6.

12. Gandotra, P.; Jha, R.K.; Jain, S. Green communication in next generation cellular networks: A survey. IEEE Access 2017, 5, 11727-11758. [CrossRef]

13. Hossain, M.S.; Raha, B.K.; Paul, D.; Haque, M.E. Optimization and generation of electrical energy using ind flow in rural area of Bangladesh, Research Journal of Applied Sciences. Eng. Technol. 2015, 10, 895-902.

14. Jahid, A.; Hossain, M.S. Intelligent energy cooperation framework for green cellular base stations. In Proceedings of the IEEE International Conference on Computer, Communication, Chemical, Material and Electronic Engineering (IC4ME2), Rajshahi, Bangladesh, 8-9 February 2018; pp. 1-6.

15. NASA. Surface Meteorology and Solar Energy: A Renewable Energy Resource. Available online: https: / / eoswebarcasa.gov/sse/ (accessed on 10 January 2020).

16. Mondal, M.A.H.; Islam, A.K.M.S. Potential and viability of grid connected solar PV system in Bangladesh. Renew. Energy 2011, 36, 1869-1874. [CrossRef]

17. Huda, A.S.N.; Mekhilef, S.; Ahsan, A. Biomass energy in Bangladesh: current status and prospects. Renew. Sustain. Energy Rev. 2014, 30, 504-517. [CrossRef]

18. Hossain, M.S.; Jahid, A.; Islam, K.Z.; Rahman, M.F. Solar PV and biomass resources based sustainable energy supply for off-grid cellular base stations. IEEE Access 2020, 8, 1-24, . [CrossRef]

19. Halder, P.K.; Paul, N.; Beg, M.R.A. Assessment of biomass energy resources and related technologies practice in Bangladesh. Renew. Sustain. Energy Rev. 2014, 39, 444-460. [CrossRef]

20. Food and Agriculture Organization (FAO). Rice Market Monitor 21, April 2018. Available online: http: / / www.fao.org/3/19243EN/i9243en.pdf, (accessed on 10 January 2020).

21. Hossain, M.S.; Rahman, M.F. Hybrid solar PV/Biomass powered energy efficient remote cellular base stations. Int. J. Renew. Energy Res. 2020, 10, 329-342.

22. Hossain, M.S.; Jahid, A.; Rahman, M.F. Quantifying potential of hybrid PV/WT power supplies for off-grid LTE base stations. In Proceedings of the IEEE International Conference on Computer, Communication, Chemical, Material and Electronic Engineering (IC4ME2), Rajshahi, Bangladesh, 8-9 February 2018; pp. 1-5.

23. Alsharif, M.; Kim, J. Optimal solar power system for remote telecommunication base stations: a case study based on the characteristics of South Korea's solar radiation exposure. Sustainability 2016, 8, 942. [CrossRef]

24. Jahid, A.; Hossain, M.S. Dimensioning of zero grid electricity cellular networking with solar powered off-grid BS. In Proceedings of the IEEE International Conference on Electrical \& Electronic Engineering (ICEEE), Rajshahi, Bangladesh, 4-6 November 2017; pp. 1-4.

25. Chamola, V.; Sikdar, B. Solar powered cellular base stations: current scenario, issues and proposed solutions. IEEE Commun. Mag. 2016, 54, 108-114. [CrossRef]

26. Han, T.; Ansari, N. On optimizing green energy utilization for cellular networks with hybrid energy supplies. IEEE Trans. Wirel. Commun. 2013, 12, 3872-3882. [CrossRef]

27. Anayochukwu, A.V.; Nnene, E.A. Simulation and optimization of hybrid diesel power generation system for GSM base station site in Nigeria. Electron. J. Energy Environ. 2013, 1, 37-56. [CrossRef] 
28. Alsharif, M.H.; Nordin, R.; Ismail, M. Energy optimisation of hybridoff-grid system for remote telecommunication base station deployment in Malaysia. EURASIP J. Wirel. Commun. Netw. 2015, 2015, 1-16. [CrossRef]

29. Jahid, A.; Monju, M.K.I.; Hossain, M.S.; Hossain, M.F. Hybrid power supply solutions for off-grid green wireless networks. Int. J. Green Energy 2018, 16, 12-33. [CrossRef]

30. Jahid, A.; Monju, M.K.H.; Hossain, M.E.; Hossain, M.F. Renewable energy assisted cost aware sustainable off-grid base stations with energy cooperation. IEEE Access 2018, 6, 60900-60920. [CrossRef]

31. Alsharif, M.H.; Kim, J. Hybrid off-grid SPV/WTG power system for remote cellular base stations towards green and sustainable cellular networks in South Korea. Energies 2016, 10, 9. [CrossRef]

32. Singh, S.; Singh, M.; Kaushik, S.C. A review on optimization techniques for sizing of solar-wind hybrid energy systems. Int. J. Green Energy 2016, 13, 1564-1578. [CrossRef]

33. Bajpai, P.; Prakshan, N.P.; Kishore, N.K. Renewable hybrid stand-alone telecom power system modeling and analysis. In Proceedings of the IEEE Region 10 Conference, Singapore, 23-26 November 2009; pp. 1-6.

34. Liu, K.; Zou, C.; Li, K.; Wik, T. Charging pattern optimization for lithium-ion batteries with an electrothermal-aging model. IEEE Trans. Ind. Inform. 2018, 14, 5463-5474. [CrossRef]

35. Liu, K.; Hu, X.; Yang, Z.; Xie, Y.; Feng, S. Lithium-ion battery charging management considering economic costs of electrical energy loss and battery degradation. Energy Convers. Manag. 2019, 195, 167-179. [CrossRef]

36. Jahid, A.; Ahmad, A.S.; Hossain, M.F. Energy efficient BS Cooperation in DPS CoMP based cellular networks with hybrid power supply. In Proceedings of the IEEE International Conference on Computer and Information Technology (ICCIT), Dhaka, Bangladesh, 18-20 December 2016; pp. 93-98.

37. Hossain, M.S.; Rahman, M.; Sarker, M.T.; Haque, M.E.; Jahid, A. A Smart IoT based system for monitoring and controlling the sub-station equipment. Internet Things 2019, 7, 1-16. [CrossRef]

38. Jahid, A.; Shams, A.B.; Hossain, M.F. Energy cooperation among BS with hybrid power supply for DPS CoMP based cellular networks. In Proceedings of the IEEE International Conference on Electrical, Computer \& Telecommunication Engineering (ICECTE), Rajshahi, Bangladesh, 8-10 December 2016; pp. 1-4.

39. Chia, Y.K.; Sun, S.; Zhang, R. Energy cooperation in cellular networks with renewable powered base stations. IEEE Trans. Wirel. Commun. 2014, 13, 6996-7010. [CrossRef]

40. Jahid, A.; Islam, M.S.; Hossain, M.S.; Hossain, M.E.; Monju, M.K.H.; Hossain, M.F. Toward energy efficiency aware renewable energy management in green cellular network with joint coordination. IEEE Access 2019, 7, 75782-75797. [CrossRef]

41. Huang, P.; Sun, S.; Liao, W. GreenCoMP: Energy-aware cooperation for green cellular networks. IEEE Trans. Mob. Comput. 2017, 16, 143-157. [CrossRef]

42. Leithon, J.; Lim, T.J.; Sun, S. Energy exchange among base stations in a cellular network through the smart grid. In Proceedings of the IEEE International Conference on Communications (ICC), Sydney, Australia, 10-14 June 2014; pp. 4036-4041.

43. Farooq, M.J.; Ghazzai, H.; Kadri, A.; ElSawy, H.; Alouini, M. A hybrid energy sharing framework for green cellular networks. IEEE Trans. Commun. 2017, 65, 918-934. [CrossRef]

44. Antonopoulos, A.; Kartsakli, E.; Bousia, A.; Alonso, L.; Verikoukis, C. Energy-efficient infrastructure sharing in multi-operator mobile networks. IEEE Commun. Mag. 2015, 53, 242-249. [CrossRef]

45. Bousia, A.; Kartsakli, E.; Antonopoulos, A.; Alonso, L.; Verikoukis, C. Game-theoretic infrastructure sharing in multioperator cellular networks. IEEE Trans. Veh. Technol. 2016, 65, 3326-3341, . [CrossRef]

46. Gong, J.; Thompson, J.S.; Zhou, S.; Niu, Z. Base station sleeping and resource allocation in renewable energy powered cellular networks. IEEE Trans. Commun. 2014, 62, 3801-3813. [CrossRef]

47. Zhang, S.; Zhang, N.; Zhou, S.; Gong, J.; Niu, Z.; Shen, X. Energy-aware trafc ofoading for green heterogeneous networks. IEEE J. Sel. Areas Commun. 2016, 34, 1116-1129, . [CrossRef]

48. Jahid, A.; Shams, A.B.; Hossain, M.F. Dynamic point selection CoMP enabled hybrid powered green cellular networks. Comput. Electr. Eng. 2018, 72, 1006-1020. [CrossRef]

49. Kanwal, K.; Safdar, G.A.; Ur-Rehman, M.; Yang, X. Energy management in LTE networks. IEEE Access 2018, 5, 4264-4284, . [CrossRef]

50. Xu, B.; Chen, Y.; Carrión, J.R.; Loo, J.; Vinal, A. Energy-aware power control in energy cooperation aided millimeter wave cellular networks with renewable energy resources. IEEE Access 2016, 5, 432-442, . [CrossRef] 
51. Shams, A.B.; Jahid, A.; Hossain, M.F. A CoMP based LTE-a simulator for green communications. In Proceedings of the IEEE International Conference on Wireless Communications, Signal Processing and Networking (WiSPNET), Chennai, India, 22-24 March 2017; pp. 1751-1756.

52. Jahid, A.; Shams, A.B.; Hossain, M.F. Energy efficiency of JT CoMP based green powered LTE-A cellular networks. In Proceedings of the IEEE International Conference on Wireless Communications, Signal Processing and Networking (WiSPNET), Chennai, India, 22-24 March 2017; pp. 1739-1745.

53. Jahid, A.; Shams, A.B.; Hossain, M.F. PV Powered CoMP based green cellular networks with standby grid supply. Int. J. Photoenergy 2017, 2017, 1-14. [CrossRef]

54. Hung, H.J.; Ho, T.Y.; Lee, S.Y.; Yang, C.Y.; Yang, D.N. Relay selection for heterogeneous cellular networks with renewable green energy sources. IEEE Trans. Mob. Comput. 2018, 17, 661-674. [CrossRef]

55. Liu, C.; Natarajan, B. Power management in heterogeneous networks with energy harvesting base stations. Phys. Commun. 2015, 16, 14-24. [CrossRef]

56. Auer, G.; Giannini, V.; Desset, C.; Godor, I.; Skillermark, P.; Olsson, M.; Imran, M.A.; Sabella, D.; Gonzalez, M.J.; Blume, O.; et al. How much energy is needed to run a wireless network? IEEE Wirel. Commun. 2011, 18, 40-49. [CrossRef]

57. MAlsharif; Kim, J.; Kim, J. Opportunities and challenges of solar and wind energy in South Korea: A review. Sustainability 2018, 10, 1822. [CrossRef]

58. Alsharif, M.; Kim, J.; Kim, J. Energy optimization strategies for eco-friendly cellular base stations. Energies 2018, 11, 1500. [CrossRef]

59. Chauhan, A.; Saini, R.P. A review on integrated renewable energy system based power generation for stand-alone applications: Configurations, storage options, sizing methodologies and control. Renew. Sustain. Energy Rev. 2014, 38, 99-120. [CrossRef]

60. MIslam, S.; Akhter, R.; Rahman, M.A. A thorough investigation on hybrid application of biomass gasifier and PV resources to meet energy needs for a northern rural off-grid region of Bangladesh: A potential solution to replicate in rural off-grid areas or not? Energy 2018, 145, 338-355. [CrossRef]

(C) 2020 by the authors. Licensee MDPI, Basel, Switzerland. This article is an open access article distributed under the terms and conditions of the Creative Commons Attribution (CC BY) license (http:/ / creativecommons.org/licenses/by/4.0/). 